EMÍLIO MENDONÇA DIAS DA SILVA

\title{
DIREITO INTERNACIONAL E COERÊNCIA SISTÊMICA: O RELATÓRIO DA COMISSÃO DE DIREITO INTERNACIONAL SOBRE FRAGMENTAÇÃO APÓS UM DECÊNIO
}

DISSERTAÇÃO DE MESTRADO

ORIENTADOR: PROFESSOR TITULAR DOUTOR PAULO BORBA CASELLA

UNIVERSIDADE DE SÃO PAULO

FACULDADE DE DIREITO

São Paulo - SP 

EMÍLIO MENDONÇA DIAS DA SILVA

\title{
DIREITO INTERNACIONAL E COERÊNCIA SISTÊMICA: O RELATÓRIO DA COMISSÃO DE DIREITO INTERNACIONAL SOBRE FRAGMENTAÇÃO APÓS UM DECÊNIO
}

\begin{abstract}
Dissertação de Mestrado apresentada a Banca Examinadora do Programa de Pós-Graduação em Direito da Faculdade de Direito da Universidade de São Paulo, na área de concentração de direito internacional público, sob orientação do Prof. Dr. Paulo Borba Casella.
\end{abstract}

UNIVERSIDADE DE SÃO PAULO

FACULDADE DE DIREITO

São Paulo - SP 
Catalogação da Publicação

\title{
Serviço de Biblioteca e Documentação
}

Faculdade de Direito da Universidade de São Paulo

\author{
Silva, Emílio Mendonça Dias da \\ Direito Internacional e Coerência Sistêmica: o
}

Relatório da Comissão de Direito Internacional sobre

Fragmentação Após um Decênio. / Emílio Mendonça Dias da

Silva ; orientador Paulo Borba Casella -- São Paulo,

2017.

$185 \mathrm{p}$

Dissertação (Mestrado - Programa de Pós-Graduação em Direito Internacional) - Faculdade de Direito, Universidade de São Paulo, 2017.

1. Fragmentação, unidade e coerência. 2. Conflitos normativos. 3. Relatório da Comissão de Direito Internacional da ONU. I. Casella, Paulo Borba, orient. II. Título. 
Nome: SILVA, Emílio Mendonça Dias da

Título: Direito Internacional e Coerência Sistêmica: o Relatório da Comissão de Direito Internacional Sobre Fragmentação Após um Decênio.

Dissertação apresentada à Faculdade de Direito da Universidade de São Paulo como exigência parcial para obtenção do título de Mestre em Direito.

Aprovado em:

Banca Examinadora

Prof.Dr. Instituição:

Julgamento: Assinatura:

Prof.Dr. Instituição:

Julgamento: Assinatura:

Prof.Dr. Instituição:

Julgamento: Assinatura: 
Aos meus pais, Sérgio e Vera, e às minhas irmãs, Larissa e Letícia, os quais, cada qual a seu modo, muito me incentivaram durante e sobre todos os aspectos da minha vida. Às minhas recém falecidas tias, Alzira $e$ Darcy, duas educadoras e grandes entusiastas do conhecimento, as quais certamente ficariam orgulhosas de mim.

Ao meu avô, Francisco, também recentemente falecido, o qual, mesmo longe, sei que sempre torceu por mim. 


\section{AGRADECIMENTO}

Agradeço a orientação do Professor Paulo Borba Casella, certamente uma das grandes referências no estudo do direito internacional público no Brasil. É muito satisfatório ser orientado por quem acredita no direito internacional público e se empenha para que, cada vez mais, seu estudo se faça ouvido pela academia, poder público e sociedade.

Agradeço também a todos os funcionários da Faculdade de Direito da Universidade de São Paulo, os quais muito contribuem para esta instituição de qualidade notória, e não pouparam esforços para me ajudar quando precisei.

Agradeço a toda a comunidade acadêmica, a qual dá vitalidade e inspira questionamentos cada vez mais profundos sobre o direito e sobre as relações e condicionamentos sociais de um modo geral, motivando a produção acadêmica e dando vida à consciência crítica. 


\section{RESUMO}

Emílio Mendonça Dias da Silva. Direito Internacional e Coerência Sistêmica: o Relatório da Comissão de Direito Internacional sobre Fragmentação Após um Decênio. 185 páginas. Mestrado - Faculdade de Direito da Universidade de São Paulo. São Paulo. 13 de janeiro de 2017.

Diante da expansão e diversificação do direito internacional público, das quais emergiram dúvidas sobre sua capacidade de conservar um sentido integrado ou se estaria sendo fragmentado, seja por ausência de normas que integrem os órgãos judicantes ou mesmo por ausência de critérios que calibrem a relação entre conjuntos normativos orientados a oferecer soluções jurídicas para diferentes demandas, a Comissão de Direito Internacional das Nações Unidas, constituindo um grupo de estudos para análise de tal questão em 2000, produziu um relatório abordando a possível fragmentação do direito internacional a partir dos potenciais conflitos normativos. O relatório foi concluído e apresentado em 2006, e, de lá para cá, causou relevante impacto sobre o trabalho de estudiosos do direito internacional, sobretudo aqueles que se dedicam a questões como fragmentação, unidade, coerência ou conflitos de normas. Este trabalho fará um levantamento de análises sobre o relatório, bem como eventuais influências indiretas em outras literaturas, relacionando-as aos próprios argumentos contidos no relatório, a fim de avaliar o impacto que ele produziu ao estudo do tema, transcorrido um decênio de sua conclusão.

Palavras-chave: Fragmentação ou Unidade. Coerência. Comissão de Direito Internacional das Nações Unidas. Relatório. Impacto. 


\begin{abstract}
Emílio Mendonça Dias da Silva. International Law and Systemic Coherence: the International Law Comission Report on Fragmentation After a Decennial. 185 pages. Master - Faculty of Law, University of São Paulo. São Paulo. 13h january 2017.

Face to expansion and diversification of public international law, of which it has arisen doubts about its capacity to conserve an integrated meaning or if it is being fragmented, by the absence of norms which integrate adjudicatory bodies or by the absence of norms which calibrate the relation among normative clusters shaped to design legal response to different demands, International Law Commission, constituting a study group to address such concern in 2000, produced a report, approaching the possible fragmentation of international law from potential normative conflicts. The report was concluded and presented in 2006 and, since then, it has caused relevant impact on the works of international law scholars, principally those who dedicate to analyse concerns such as fragmentation, unity, coherence or normative conflicts. This work will map analysis on the report, as well as indirect influences over other writtings, relating to the arguments contained in the report, in order to evaluate the impact it has produced on the matter, after a decennial of its conclusion.
\end{abstract}

Keywords: Fragmentation or unity. Coherence. International Law Commission of United Nations. Report. Impact. 


\section{SUMÁRIO}

INTRODUÇÃO. 11

CAPÍTULO I: DIREITO INTERNACIONAL E O DEBATE SOBRE SUA

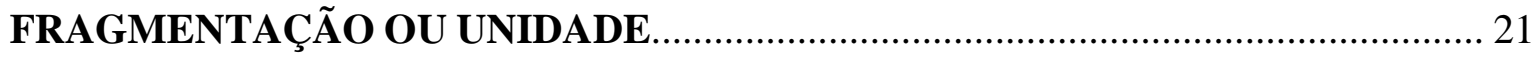

1.1. Fragmentação do direito internacional: possíveis significados...................................... 23

1.1.1. A dimensão institucional da fragmentação............................................................. 29

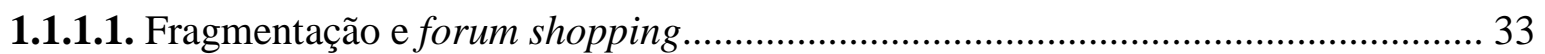

1.1.2. A dimensão sociológico-jurídica da fragmentação................................................ 35

1.2. Oposição à ideia de fragmentação do direito internacional............................................. 37

1.2.1. A percepção de constitucionalismo no direito internacional como eventual contraponto à ideia de fragmentação........................................................................ 43

1.3. Fragmentação como tendo aspectos negativos e positivos e fragmentação e constitucionalismo como fenômenos coexistentes.......................................................... 47

CAPÍTULO II: A DISCUSSÃO SOBRE 'LEX SPECIALIS' E A FORMAÇÃO DE REGIMES AUTÔNOMOS NO DIREITO INTERNACIONAL ……………………... 50

2.1. A fragmentação nos três tipos de conflito identificados pelo relatório......................... 51

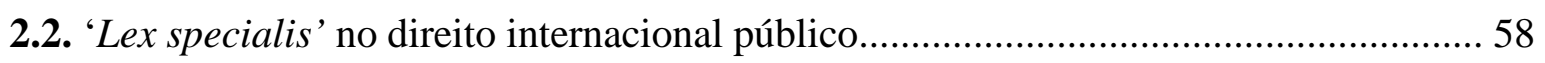

2.3. 'Lex specialis' e regimes autônomos (self-contained regimes)..................................... 68

2.3.1. O problema de definição de "regimes autônomos"................................................... 68

2.3.2. Regimes autônomos: o debate sobre sistema e subsistemas de responsabilidade

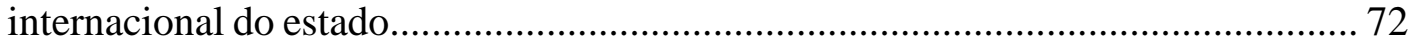

2.3.3. Condições para a formação de regimes e sua relação com o direito geral .............. 75

2.4. Direito geral especial? Normas primárias e secundárias?........................................... 83

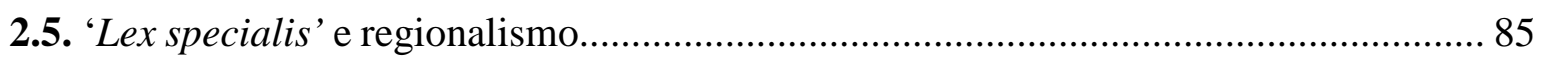

CAPÍTUlo III: A DISCUSSÃo SOBRE FRAGMENTAÇÃo E NORMAS SUCESSIVAS NO DIREITO INTERNACIONAL .................................................... 92

3.1. O relatório e o debate sobre conflito entre normas sucessivas...................................93

3.2. A discussão sobre o artigo 30 da Convenção de Viena sobre o Direito dos Tratados de 1969. 
3.3. Norma anterior e posterior: validade ou prioridade?

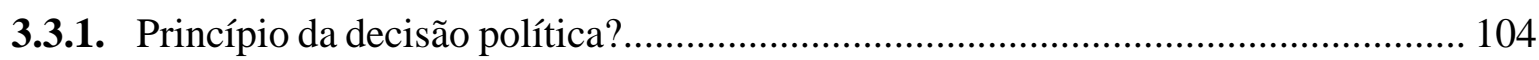

3.4. Cláusulas especiais que tratam da relação entre tratados............................................ 105

3.5. Acordos inter se que importam modificação de um tratado....................................... 109

3.6. A conclusão do relatório sobre normas sucessivas e fragmentação........................... 114

CAPÍTULO IV: JUS COGENS, CARTA DAS NAÇÕES UNIDAS, OBRIGAÇÕES $\begin{array}{llllll}\text { ERGA OMNES E A } & \text { FRAGMENTAÇÃO DO DIREITO }\end{array}$

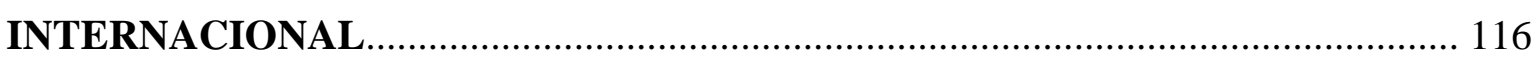

4.1. Normas superiores: jus cogens e a Carta das Nações Unidas.................................. 117

4.2. A discussão do relatório sobre normas conflitantes com a Carta das Nações Unidas.

4.3. $\quad$ O estudo do relatório sobre jus cogens e sua capacidade de solução de conflito normativo.

4.4. O estudo do relatório sobre obrigações erga omnes.

4.5. Conclusões do relatório sobre a prevalência da Carta das Nações Unidas, jus cogens e obrigações erga omnes. 134

CAPÍTULO V: FRAGMENTAÇÃO DO DIREITO INTERNACIONAL E

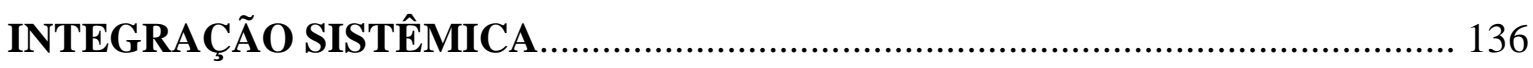

5.1. A Convenção de Viena sobre o Direito dos Tratados e integração sistêmica

5.1.1. A aplicação do artigo 31(3)(c) da CVDT. 139

5.2. A proposta da técnica de balanceamento. 149

5.3. Conclusões do relatório sobre "integração sistêmica". 150 CONCLUSÃO 153 


\begin{abstract}
ABREVIATURAS
CDI - Comissão de Direito Internacional das Nações Unidas.

CEDH - Corte Europeia de Direitos Humanos.

CIJ - Corte Internacional de Justiça

CNUDM - Convenção das Nações Unidas sobre o Direito do Mar.

CVDT - Convenção de Viena sobre o Direito dos Tratados de 1969.

OMC - Organização Mundial do Comércio.

ONU - Organização das Nações Unidas.

OSC - Órgão de Solução de Controvérsias da Organização Mundial do Comércio.

TPII - Tribunal Penal Internacional para a Antiga Iugoslávia.
\end{abstract}




\section{INTRODUÇÃO}

O direito internacional ${ }^{1}$ conviveu com formidável - alguns dirão conturbada extensão dos campos sobre os quais deva oferecer solução jurídica, assim como um progressivo grau de diversificação, entendendo-se por isso não apenas o aumento de conteúdo, mas sua divisão em linhas temáticas a constituírem-se como "ramos" específicos de seu estudo. Às expansão e diversificação acompanha um aumento de instituições permanentemente estabelecidas para gerenciamento de demandas internacionalizadas. Particularmente na década de 1990, houve intensa criação de órgãos voltados à solução de controvérsias internacionais, o que suscitou suspeitas, por parte de alguns de seus estudiosos, sobre a capacidade do direito internacional em preservar sua uniformidade ou coerência. Os que entenderam haver um forte distanciamento de ditos conteúdos, sem apropriada vinculação ou interconexão entre eles, passaram a falar em "fragmentação" do direito internacional, sendo esta uma preocupação tanto institucional - a proliferação de tribunais internacionais, a partir da qual diferenças jurisprudenciais possam ser acentuadas sem a consentânea uniformização -, como substantiva, a tratar especificamente de conjuntos de normas adstritos temática ou territorialmente os quais reivindicam independência frente ao direito internacional geral, ao consagrar pressupostos, princípios e institutos próprios. Esta visão é geralmente confrontada por aqueles que ou proclamam sua unidade e coerência, ou descrevem o direito internacional a partir de fenômeno distinto e vocacionado à hierarquização e sistematização: a "constitucionalização".

Oportunamente, a Comissão de Direito Internacional das Nações Unidas (CDI) decidiu promover estudo sobre a questão, o qual é compatível com a atribuição deste órgão, a lembrar que, atendendo ao artigo 13 da Carta das Nações Unidas, segundo o qual a Assembleia Geral deve promover estudos sobre o desenvolvimento progressivo e a codificação do direito internacional, criou, aprovando seu Estatuto por meio da Resolução 174 (II) de 21 de novembro de 1947, a Comissão de Direito Internacional das Nações Unidas para esta finalidade. O artigo 15 do Estatuto esclarece que o termo "codificação" significa "formulação" e "sistematização" de normas internacionais; de sorte que o debate sobre fragmentação, unidade ou coerência é evidentemente uma questão de sistematização do

\footnotetext{
${ }^{1}$ Por direito internacional, neste trabalho, entenda-se o direito internacional público. O chamado "direito internacional privado" não constitui seu objeto de estudo.
} 
direito internacional, pois versa sobre a possibilidade ou impossibilidade de associação e de criação de critérios jurídicos que calibrem a relação entre normas, ou entre seus corpos especializados, de maneira que toda a composição do direito internacional possa ser descrita como sistema.

A inclusão do tema na agenda da CDI foi decidida na 52 $2^{\mathrm{a}}$ sessão, em 2000, a partir da recomendação de Gerhard HAFNER. Sua proposta, intitulada "risks ensuing from fragmentation of international law", faz alusão ao fim da guerra fria e ao crescente aumento da fragmentação política acompanhado de interdependência global e regional no tocante a áreas vitais para as relações internacionais, como economia, ambiente, energia, recursos, saúde e proliferação de armas de destruição em massa. Lembra que mesmo em trabalhos anteriores da Comissão entendeu-se não haver uma ordem jurídica homogênea, mas partes erráticas e elementos diferentemente estruturados, os quais contém um lado positivo por garantirem a submissão de demandas sociais internacionalizadas ao direito, mas que igualmente podem resultar em fricções e contradições a ameaçar a consistência do direito internacional. O problema deveria, para ele, ser estudado pela Comissão, porquanto afeta a estabilidade do sistema jurídico internacional. Algumas características do direito internacional são levantadas por HAFNER para esclarecer o porquê da fragmentação do direito internacional: não há órgãos centralizados, as instituições do sistema internacional não impõem subordinação senão conduzem coordenação; a coerência do direito internacional estaria sendo ameaçada pelo crescente grau de especialização em linhas setoriais; há diferentes estruturas de conjuntos normativos no direito internacional, como a estrutura baseada no direito internacional clássico de relações eminentemente recíprocas entre estados, estrutura de normas insculpindo obrigações ao estado devidas aos indivíduos e estrutura de normas estabelecendo deveres oriundos e devidos a toda a comunidade de estados; há regulamentação paralela sobre os mesmos assuntos, por exemplo, no plano universal e regional; há regulação competitiva originada de diferentes regimes de direito, como as regulações comerciais e ambientais, as primeiras procurando impedir restrições ao comércio e as segundas, muitas vezes, contê-lo para fins de proteção ao ambiente; há um aumento do escopo do direito internacional o qual redunda no aumento de atores; há diferentes regimes de normas secundárias, entendendo-se como tais normas que estabelecem consequências por violações e condições sob as quais um estado pode ser considerado responsável. Enfim, HAFNER sustentou que este formato disperso do direito internacional 
promove sua desintegração, ameaça sua autoridade e credibilidade. Recomendou, portanto, a elaboração de um relatório ${ }^{2}$.

A proposta foi aceita pela CDI na reunião 2717 de 8 de maio de 2002, presidida por Robert ROSENSTOCK. Para a composição deste grupo, Bruno SIMMA (Alemanha) foi designado à presidência, e teve como membros Emmanuel Akwei ADDO (Gana), Ian BROWNLIE (Reino Unido), Enrique CANDIOTI (Argentina), Christopher John Robert DUGARD (África do Sul), Paula ESCARAMEIA (Portugal), Giorgio GAJA (Itália), Zdzislaw GALICKI (Polônia), Maurice KAMTO (Camarões), James Lutabanzibwa KATEKA (Tanzânia), Fathi KEMICHA (Tunísia), Martii KOSKENNIEMI (Finlândia), William MANSFIELD (Nova Zelândia), Djamchid MOMTAZ (Irã), Bernd NIEHAUS (Costa Rica), Guillaume PAMBOU-TCHIVOUNDA (Gabão), Alain PELLET (França), Pemmaraju Sreenivasa RAO (Índia), Roberto ROSENSTOCK (Estados Unidos da América), Bernardo SEPÚlVEDA (México), Peter TOMKA (Eslováquia), Hanqin XUE (China), Chusei YAMADA (Japão) e Valery KUZNETSOV (Rússia). Em uma primeira discussão, ocorrida na 54 ${ }^{\mathrm{a}}$ sessão, em 2002, o grupo decidiu tomar a argumentação de HAFNER como ponto de partida para seu estudo, como também definiu que o problema da fragmentação seria tratado como consequência de sua expansão e diversificação; e que o grupo de estudos, apesar da extrema complexidade da questão, poderia ser produtivo sobre aspectos específicos, a oportunizar que o estudo se mantenha e se aprofunde. Houve também consenso de que a fragmentação do direito internacional não poderia ser tida como um fenômeno novo. Além disso, o grupo afirmou que seria importante abordar os aspectos positivos do fenômeno, como por exemplo, tratar-se de um sinal de vitalidade do direito internacional; ou que a proliferação de normas, regimes e instituições representaria fortalecimento do direito internacional, visto que novas áreas são submetidas à sua normatividade; além da possível conveniência em se tratar de um sistema jurídico constituído por vozes plurais, sendo, por isso, policêntrico. O título do trabalho foi considerado inapropriado nesta ocasião, 'Risks Ensuing from Fragmentation of International Law', por sua concepção preconcebidamente negativa: este deveria ser substituído por "difficults arising from the diversification of international law". O grupo trataria fragmentação como consequências indesejadas do processo de expansão e diversificação. Já nesta reunião, por outro lado, definiram-se algumas orientações ao trabalho, abstendo-se de

2 HAFNER, Gerhard; Risks Ensuing From Fragmentation of International Law; Syllabuses on Topics Recommended for Inclusion in the Long-Term Programme of Work of the Comission (A/55/10) -2000. 
esclarecer neste estágio qual metodologia seria adotada. Decidiu-se pela produção de um trabalho explanatório, o qual não abordaria a criação e a relação entre órgãos judicantes, apesar de que o estudo deveria considerar a possibilidade de normas serem aplicadas de modo diferente por eles. Tampouco se produziria estudo de comparação das ordens domésticas com o sistema internacional, visto que este seria completamente diferente daquelas, sobretudo em termos de hierarquia normativa. Alguns temas foram inicialmente propostos como relevantes ao estudo, a saber: a função e o escopo da lex specialis e regimes autônomos; a interpretação de tratados à luz de qualquer norma relevante à relação entre as partes, nos termos do artigo 31 (3) (c) da Convenção de Viena sobre o Direito dos Tratados de 1969 (CVDT) e a relação com o caso “camarões”, apreciado pela sistema de solução de controvérsias da Organização Mundial do Comércio (OMC); a aplicação de tratados sucessivos que regulam um mesmo assunto; a modificação de tratados multilaterais por algumas de suas partes; relações hierárquicas em direito dos tratados: jus cogens, obrigações erga omnes e o artigo 103 da Carta das Nações Unidas como formas de solução de conflitos normativos. Foi definido, nesta reunião, que Bruno SIMMA elaboraria o estudo sobre lex specialis e regimes autônomos ${ }^{3}$.

Na reunião 2758, do dia 16 de maio de 2003, o presidente do grupo, Bruno SIMMA, disse ter concluído suas consultas sobre o tema e indicou Martii KOSKENNIEMI para substituí-lo à presidência. O relatório resultado da $55^{\mathrm{a}}$ sessão ${ }^{4}$ indica que o grupo fez distinção, a partir de leituras sobre a questão, entre a perspectiva institucional - coordenação e hierarquia institucional - e substantiva do problema, tratando esta última dos conteúdos jurídicos organizados em regimes especiais os quais confrontam uns aos outros. Reforçouse a preferência do grupo pelo aspecto substantivo, assimilando três diferentes tipos de conflito a serem estudados: conflito a partir de diferentes interpretações acerca do direito internacional, tendo como foco decisões da Corte Internacional de Justiça (CIJ) e do Tribunal Penal Internacional para a antiga Iugoslávia (TPII); conflito originado de um corpo normativo especial com o direito internacional geral, cujo estudo se faria sobre o caso

\footnotetext{
${ }^{3}$ Comissão de Direito Internacional das Nações Unidas; Report of the Study Group on Fragmentation of International Law (A/CN.4/L.628); Agosto de 2002. Disponível em: http://legal.un.org/ilc/guide/1_9.shtml (último acesso: 12.11.2016).

${ }^{4}$ Este relatório tivera a participação dos seguintes membros: Martii KOSKENNIEMI, Emmanuel ADDO, Ian BROWNLIE, Choung II CHEE (República da Coreia), Pedro COMISSÁRIO AFONSO (Moçambique), Riad DAOUD (Síria), Christopher John Robert DUGARD, Paula ESCARAMEIA, Giorgio GAJA, Zdzislaw GALICKI, James Lutabanzibwa KATEKA, Fathi KEMICHA, Roman Anatolyevich KOLODKIN (Rússia), William MANSFIELD, Michael J. MATHESON (Estados Unidos da América), Teodor Viorel MELESCANU (Romênia), Djamchid MOMTAZ, Víctor Rodríguez CEDEÑO (Venezuela), Robert ROSENSTOCK (Estados Unidos da América), Bernardo SEPÚLVEDA, Hanqin XUE e Chusei YAMADA.
} 
"Belilos", apreciado pela Corte Europeia de Direitos Humanos (CEDH); conflito entre dois campos especializados do direito internacional, como o direito do comércio internacional e ambiental. Já a esta altura, o grupo observou que produziria estudo sobre critérios de solução de conflito normativo. $\mathrm{O}$ trabalho foi dividido da seguinte forma: a interpretação de tratados à luz do artigo 31 (3) (c) seria estudado por William MANSFIELD; a aplicação de tratados sucessivos sobre um mesmo assunto ficaria ao cargo de Riad DAOULI; as relações normativas hierárquicas seriam estudadas por Zdzislaw GALICKI. Na ocasião, também houve discussão a respeito da função e do escopo da lex specialis e dos regimes autônomos, diante da estudo inaugural de SIMMA sobre o tema: houve a distinção dos três tipos de conflitos, já esclarecidos, alertando-se para o fato de que a fragmentação decorrente de diferentes interpretações do direito internacional não é questão de lex specialis; considerouse a natureza de lex specialis, sua aceitação e racionalidade, o aspecto relacional da distinção entre geral e especial, e a aplicação de lex specialis sob o critério do "mesmo assunto"; entendeu-se a função de lex specialis tanto como aplicação do direito geral como exceção, devendo o estudo contemplar ambas as situações. Decidiram, apesar da divergência, que o chamado direito regional deveria ser estudado neste tópico. Sobre os chamados 'regimes autônomos', discutiu-se se seu conceito deveria se limitar a conjuntos os quais contém normas primárias e secundárias, bem como se identificou dificuldade na diferenciação de normas primárias e secundárias. Entendeu-se que lex specialis e regimes autônomos seriam discutidos sob o plano de fundo do direito internacional geral. Por outro lado, considerações extremamente abstratas, como se o direito internacional pode ser visto como um sistema único, não foram tidas como necessárias pelo grupo de estudo, de sorte que este deveria se concentrar em questões jurídicas e analíticas, assim como possíveis guias a serem considerados pela Comissão ${ }^{5}$.

Na $56^{\text {a }}$ sessão, ocorrida em 28 de julho de 2004, o grupo foi reconstituído ${ }^{6}$. Afirmou-se que o grupo produziria um trabalho coletivo, a ser apresentado à Comissão em 2006, o qual incorporaria grande parte da substância dos trabalhos individuais,

\footnotetext{
${ }^{5}$ Comissão de Direito Internacional das Nações Unidas; Report of the Study Group on Fragmentation of International Law: Difficults Arising from the Diversification and Expansion of International Law (A/CN.4/L.644); 18 de julho de 2003.

${ }^{6}$ Compuseram o grupo: Martii KOSKENNIEMI, Husain M. AL-BAHARNA (Bahrein), Choung II CHEE, Pedro COMISSÁRIO AFONSO, Ian BROWNLIE, Riad DAOUD, Paula ESCARAMEIA, Giorgio GAJA, Zdzislaw GALICKI, James Lutabanzibwa KATEKA, Fathi KEMICHA, Anatolyevich KOLODKIN, William MANSFIELD, Michael J. MATHESON, Teodor Viorel MELESCANU, Djamchid MOMTAZ, Bernardo SEPÚLVEDA, Didier Opertti BADAN (Uruguai), Pemmaraju Sreenivasa RAO, Hanqin XUE e Chusei YAMADA.
} 
complementados ou modificados, porém, ao longo das discussões do grupo. Sua proposta seria tanto conceber um estudo substantivo como oferecer guia sobre como lidar com a fragmentação do direito internacional. O presidente do grupo (KOSKENNIEMI) fez uma série de considerações a respeito de lex specialis e regimes autônomos, bem como anunciou que produziria um relatório suplementar para 2005; notou que há três diferentes sentidos nos quais o termo "regime autônomo" seria utilizado. Igualmente, Teodor MELESCANU apresentou seu estudo, nesta oportunidade, sobre normas sucessivas: considerou o estudo preparatório da Comissão de Direito Internacional à CVDT, especialmente acerca de seu artigo 30, e considerações sobre a relação de tratados sucessivos com hierarquia normativa, lex prior, lex posterior; pontuou que a emergência de tratados sucessivos sobre o "mesmo assunto" era consequência do aumento da cooperação internacional em resposta a novas demandas. A situação vista como relacionada ao tema da fragmentação seria a possibilidade de não haver identidade entre as partes as quais ratificam os tratados sucessivos. Ademais, esclareceu que o critério anunciado pela CVDT não se dá em termos de validade normativa. Não houve análise sobre suspensão e terminação de tratados internacionais. Foi aduzido, entretanto, que os estados poderiam estabelecer prioridades entre tratados sucessivos, sendo uma possível análise futura a possibilidade de os estados escolherem qual tratado cumprirá e os possíveis limites a tais escolhas, bem como se a distinção de obrigações "integrais" ou "absolutas", em contraposição a acordos inter se, poderia ser instrutiva neste ponto. Riad DOUDI, por sua vez, apresentou seu estudo sobre a modificação de tratados multilaterais por determinadas partes. Lidou-se com a possibilidade de derrogação de tratados multilaterais por acordos inter se originar duas categorias de relações jurídicas: as relações gerais e relações especiais. Neste aspecto, afirmou-se o dever de preservação dos interesses das partes no tratado original, o dever de preservação do objeto e propósito deste tratado, e a necessária distinção de obrigações "absolutas" ou "interdependentes", embora se tenha reconhecido que a CVDT não esclarece situações específicas de permissibilidade aos referidos acordos. Por isso, reputou-se oportuno revisar o estudo. William MANSFIELD apresentou estudo sobre a aplicação do artigo 31 (3) (c) da CVDT, o qual viabiliza a consideração de qualquer norma relevante entre as partes para fins de interpretação de um tratado. MANSFIELD levantou uma série de julgados em que a máxima foi aplicada. Nesta senda, sustentou que o mecanismo não tem utilidade para solução da fragmentação do direito internacional, a menos que um tratado apresente um problema sobre sua própria interpretação: este só poderia ser invocado caso houvesse falta de clareza ou ambiguidade no tratado. De todo modo, o estudioso abordou questões relacionadas ao tempo do tratado a 
ser considerado relevante; como também foi identificado um problema consistente no fato de a CVDT não dizer como este recurso se aplica no caso de não identidade entre partes de um tratado. O dispositivo tampouco esclareceria como essas outras normas devem ser levadas em consideração, qual o peso a ser atribuído a elas. Por fim, Zdzislaw GALICKI apresentou estudo sobre hierarquia normativa: jus cogens, obrigações erga omnes e o artigo 103 da Carta das Nações Unidas. O grupo de estudo decidiu que a análise deveria se limitar à capacidade de tais qualidades normativas de primazia ou prioridade resolver conflitos normativos. Porém, discutiu-se a distinção entre jus cogens e obrigações erga omnes, bem como se as últimas poderiam produzir o mesmo efeito do primeiro ${ }^{7}$.

Em 2005, ocorreu a 57 ${ }^{\mathrm{a}}$ sessão. Reafirmou-se a intenção do grupo de produzir estudo sob os auspícios da CVDT, por ser esta a análise da fragmentação em seu aspecto substantivo, excluindo-se o aspecto institucional. O estudo deveria se constituir como um guia à prática do direito internacional, bem como deveria envolver a atuação de órgãos pertencentes aos seus diferentes "ramos", para captar meios diversos de identidicação e administração de conflitos. Nesta oportunidade, convencionou-se que o estudo se dividiria em duas partes: a primeira direcionada à percepção do fenômeno da fragmentação; e uma segunda que faria alusão a conclusões, guias e princípios identificados ao longo do estudo. Particularmente, discutiu-se um memorando sobre "regionalismo", e o ocasional sentido jurídico que o termo pode denotar. Confirmou-se a decisão de que regionalismo deveria ser estudado conjuntamente com a função e o escopo da lex specialis e regimes autônomos, aplicando-se conclusões similares destes naquele. Normas regionais, ou conjuntos delas, deveriam ser tratadas como um tipo de lex specialis, apesar de ter havido divergências sobre dita associação. De toda sorte, decidiu-se que o estudo sobre regionalismo não deveria abarcar discussões sobre relativismo cultural, tendo escopo mais estritamente técnicojurídico. No seio da discussão sobre regionalismo, entendeu-se necessária, também, a promoção de estudo sobre "cláusulas de desconexão". Sobre o debate a respeito do artigo 31 (3) (c) da CVDT, revisou-se o original estudo de William MASFIELD: entendeu-se que o dispositivo oportunizaria interpretar tratados sob sua relação com outros, o que permitiria entender o direito internacional enquanto sistema. Preferiu-se falar em "objetivo" de integração sistêmica, em vez de "princípio". Ademais, concordou-se que a integração

7 Comissão Internacional de Direito Internacional; Report of the Study Group on Fragmentation of International Law: Difficults Arising from the Diversification and Expansion of International Law (A/CN.4/L.663/Rev. 1); 28 de julho de 2004. 
sistêmica contemplaria o costume e os princípios gerais do direito. O Trabalho de GALICKI foi igualmente revisado: houve discussão sobre jus cogens, obrigações erga omnes e o artigo 103 da Carta das Nações Unidas como formas de solucionar conflitos normativos. Tais elementos indicariam uma hierarquização do direito internacional, de modo que o estudo não excluiria outras formas. Todas as categorias normativas conteriam dificuldades próprias: não há uma norma jurídica indicando quais normas correspondem a jus cogens; as obrigações erga omnes possuem caráter demasiado genérico e envolvem o interesse jurídico de todos os estados; a previsão do artigo 103 da Carta das Nações Unidas só se aplica aos seus membros ${ }^{8}$.

Finalmente, na $58^{\mathrm{a}}$ sessão, em 13 de abril de 2006, foi apresentada a versão final do relatório do grupo de estudos da Comissão de Direito Internacional das Nações Unidas: "Fragmentação do Direito Internacional: Dificuldades Advindas da Diversificação e Expansão do Direito Internacional", o qual foi finalizado por Martii KOSKENNIEMI.

Para fins de praticidade, neste trabalho, o estudo da CDI será referido por "relatório". Além da introdução, ele contém cinco capítulos: o primeiro trata de fragmentação enquanto fenômeno, visando identificar seus possíveis efeitos e significados; o segundo versa sobre conflitos entre norma especial e norma geral - incorporando os estudos sobre lex specialis, regimes autônomos e regionalismo; o terceiro analisa conflitos entre normas sucessivas, o qual incorpora a modificação de tratados por acordos inter se e as chamadas "cláusulas de desconexão"; o quarto avalia relações de importância normativa, jus cogens, obrigações erga omnes e artigo 103 da Carta das Nações Unidas; e o último presta-se a estudar a integração sistêmica - artigo 31 (3) (c) da CVDT.

O relatório é o objeto de estudo da presente pesquisa. Pretende-se aferir cada argumento constante de sua versão final, e relacioná-lo a outros escritos posteriores, a fim de se compreender o impacto que o relatório produziu tanto na literatura que problematiza fragmentação e unidade do direito internacional, como aquela que cuida da solução de conflitos normativos nesta dimensão do direito. Estudos os quais tratam de uma categoria temática específica do direito internacional e que, seja para demonstrar os efeitos de

\footnotetext{
8 Comissão Internacional de Direito Internacional; Report of the Study Group on Fragmentation of International Law: Difficults Arising from the Diversification and Expansion of International Law (A/CN.4/L.676/Rev. 1); 29 de julho de 2005.
} 
fragmentação sobre tais domínios seja para avaliar possíveis interseções temáticas e, para tanto, recorrem aos argumentos do relatório, também serão contemplados.

Uma vez que a presente dissertação se volta à discussão de cada ponto tratado pelo relatório, seguir-se-á, de maneira geral, sua organização. O primeiro capítulo pretende contextualizá-lo, porquanto as impressões gerais do relatório coletam pressupostos desenvolvidos por toda a discussão sobre unidade, fragmentação e coerência a qual o antecedeu. É o único capítulo que não se ocupa em saber onde o relatório deu, mas de onde ele veio. Entende-se que dito levantamento é de vital importância para compreensão do próprio relatório, especificamente acerca de seus pressupostos teóricos, como também oportuniza a reflexão sobre se o relatório adere, completa ou parcialmente, a base teórica sobre fragmentação do direito internacional. A maior parte da literatura tratada neste capítulo é anterior ao relatório, o que se justifica por sua finalidade, embora, quando salutar à compreensão das diferentes perspectivas contidas no debate, recorreu-se a escritos posteriores. A este corpo de estudos, o primeiro capítulo do relatório, o qual trata da fenomenologia da fragmentação do direito internacional, é relacionado.

Por seu turno, o segundo capítulo trata do estudo do relatório sobre lex specialis e regimes autônomos. Os termos do relatório sobre este ponto são contrapostos a literaturas posteriores que se dedicaram ao mesmo assunto. Ora tais estudos são críticas diretas ao relatório, ora são posicionamentos que o tem como demonstração acerca da realidade da especialização temática e territorial no direito internacional, os quais a ele recorrem para analisar seus efeitos sobre campos também específicos.

O terceiro capítulo se ocupa da análise final do relatório acerca da relação entre normas sucessivas no direito internacional, o que, igualmente, é relacionado a escritos posteriores. Demonstrar-se-ão seus efeitos na literatura jurídica, como igualmente as posteriores avaliações sobre a capacidade da CVDT, neste aspecto, solucionar conflitos normativos.

O quarto capítulo lida com a discussão do relatório sobre elementos de hierarquização normativa no direito internacional: jus cogens, obrigações erga omnes, e o 
artigo 103 da Carta das Nações Unidas. Embora não seja o mais controvertido entre todos os temas tratados pelo relatório, há críticas pontuais às suas conclusões.

Finalmente, o quinto capítulo cuida da discussão do relatório sobre o artigo 31 (3) (c) da CVDT, correspondendo ao objetivo de integração sistêmica. Este capítulo esclarecerá sua repercussão acadêmica, como os três anteriores. Há neste caso, também, consideráveis críticas dirigidas à abordagem do relatório.

Nestes termos, após percorrido todos esses passos, pretende-se analisar o impacto do relatório sobre a discussão acerca da unidade, coerência ou fragmentação do direito internacional.

O debate sobre a coerência sistêmica do direito internacional é extremamente rico ao seu conhecimento enquanto estrutura jurídica, como também serve para a percepção e críticas sobre o sentido e o futuro desta dimensão do direito. Conhece-se melhor o direito internacional a partir da análise da interação entre normas ou de órgãos voltados a aplicálas. Por isso, independentemente da posição que se venha a tomar, entre fragmentação ou unidade, seu estudo parece sempre importante e convidativo. O presente trabalho enxerga o estudo do relatório produzido pela CDI como absolutamente relevante ao tema, sobretudo considerando as atribuições deste órgão, assim como tem como irrefragavelmente salutar a análise de seu impacto na literatura jurídica internacional.

Por outro lado, alerta-se que fragmentação, unidade e coerência são percepções sobre o todo do direito internacional. Disso resulta que, além do tema apresentar alto grau de dificuldade, ricos conteúdos são incluídos em propostas delimitadas. Inevitavelmente, o pesquisador terá de escolher uma abordagem de estudo, entre tantas possíveis. Muitas vezes argumentos centrais ao debate não são incluídos em trabalhos específicos sobre o tema, o que faz com que cada leitura seja um "garimpo". Para obter êxito na produção deste trabalho, procurou-se escritos mais intimamente ligados às questões debatidas pelo relatório. 


\section{CONCLUSÃO}

De modo algum pode-se compreender o relatório da Comissão de Direito Internacional das Nações Unidas como uma visão segundo a qual a expansão e diversificação do direito internacional tenham minado a unidade ou a possibilidade de unidade desta dimensão do direito. $\mathrm{O}$ fenômeno da fragmentação não é tido pelo relatório nem como um esfacelamento do sistema jurídico internacional, nem mesmo como ameaças às suas unidade e coerência. Prova disto é a afirmação, contida na conclusão do capítulo sobre lex specialis e regimes autônomos, de que não há qualquer perigo sério à pratica jurídica advindo de problemas de substância do direito internacional, já que a especialização e organização do estudo do direito em "ramos" é normal; e juízos associativos entre esferas especiais de operação normativa, estabelecendo-se relações de prioridade ou hierarquia, são comuns ao raciocínio jurídico. O relatório chega a afirmar que, sendo o fenômeno próprio da complexidade social e globalização as quais afetam o direito internacional, a inaptidão para lidar com tais influxos não expõe um problema do direito internacional, mas da criatividade dos juristas: o problema não residiria em sua "caixa de ferramentas" - para usar os termos do próprio relatório -, mas em sua imaginação sobre como utilizá-las ${ }^{418}$. Em seu desenvolvimento, o relatório incorpora aquilo que Bruno SIMMA considera ser o maior avanço na discussão acerca da fragmentação, consistente em não a tratar como imediata e essencialmente negativa, distanciando-se de visões que a tem como ameaça à unidade sistêmica do direito internacional, mas apenas tratando-a como "dificuldades" oriundas do maior grau de complexidade que o direito internacional assumiu. O próprio título dado ao relatório é expressivo disto, como também observa SIMMA, já que associa termos com conotações positivas e negativas - fragmentação e dificuldades; expansão e diversificação ${ }^{419}$. Já em seu título, inclusive - levando em consideração a crítica de MARTINEAU segundo a qual o debate é irrefragavelmente imbuído de ideologia e crítica, de modo que o termo "fragmentação" somente seja empregado pelos descontentes com o

\footnotetext{
${ }^{418}$ Comissão de Direito Internacional das Nações Unidas; Op. Cit. Nota 9; pp. 114 e 115. “... the fragmentation of the substance of international law - the object of this study - does not pose any very serious danger to legal practice. It is as normal a part of legal reasoning to link rules and rule-systems to each other, as it is to separate them and to establish relations of priority and hierarchy among them. The emergence of new "branches" of the law, novel types of treaties or cluster of treaties is a feature of the social complexity of a globalizing world. If lawyers feel unable to deal with this complexity, this is not a reflection of problems in their "tool-box" but in their imagination about how to use it".

${ }^{419}$ SIMMA, Bruno; Op. Cit. Nota 94.
} 
projeto político em curso, ao que seus entusiastas titulam o fenômeno pelo termo "diversificação" 420 , impende notar que o relatório faz uso das duas expressões, no claro ímpeto de se constituir nem como um relato sobre a erosão da unidade ou da coerência do sistema jurídico internacional, nem como afirmação de sua progressiva constitucionalização.

Com efeito, pode-se ver o relatório mais como um posicionamento a favor da sistematização e hierarquia do direito internacional - apesar das dificuldades - do que como um diagnóstico de fragmentação. Observa-se esta percepção do relatório na análise de Mads ANDENAS, para quem o relatório contém "ênfase forte do direito internacional enquanto sistema com hierarquia de normas" ${ }^{" 421}$. Este também é o entendimento de Eyal BENVENISTI, o qual analisa a concepção de direito internacional enquanto sistema jurídico e, entre a escola de estudiosos geralmente dos Estados Unidos da América os quais enxergam o direito internacional como um conglomerado de normas solitárias flutuantes no abismo da anarquia internacional e juristas alemães cujo esforço se empenha no sentido da criação de um sistema jurídico coerente, situa o relatório na segunda corrente, ao sugerir que qualquer conteúdo de direito internacional esteja ao alcance da CVDT e ao se apoiar sobre conceitos como jus cogens e obrigações erga omnes ${ }^{422}$. Enfaticamente, sobretudo no capítulo sobre lex specialis e regimes autônomos, o relatório sustenta existir um sistema de direito internacional do qual os estados jamais poderiam se apartar completamente - por motivos políticos, ponderou o relatório em diálogo com PAUWELYN, mas principalmente porque material e logicamente os regimes autônomos não têm condições de reinventar o mundo, valendo-se de conceitos historicamente enraizados, tais quais “jurisdição" ou "estado", a fim de estatuir seus institutos jurídicos próprios -, apesar da ampla possibilidade de derrogação a partir da formulação de novas normas, especiais ou posteriores, multilaterais ou bilaterais.

A este respeito é imperioso notar que o relatório constitui um trabalho coletivo, o qual vislumbrou distintos posicionamentos. $\mathrm{O}$ fato de a defesa do direito internacional enquanto sistema estar mais presente no capítulo sobre lex specialis talvez se deva às variações de posicionamentos entre os próprios membros do grupo de estudo, o qual contemplou divisão de tarefas, e sobre o qual se pode compreender que há certa oscilação de narrativa. Não porque nos demais capítulos a fragmentação é vista como perniciosa e

\footnotetext{
${ }^{420}$ MARTINEAU, Anne-Charlotte; Op. Cit. Nota 9.

${ }^{421}$ ANDENAS, Mads; Op. Cit. Nota 98; p. 705.

${ }^{422}$ BENVENISTI, Eyal; The Conception of International Law as a Legal System; German Yearbook of International Law; Vol. 50; 2008.
} 
irrecuperável, mas porque não parece haver ênfase tão forte na qualificação do direito internacional enquanto sistema coerente - acusando, inclusive, a falta de criatividade de juristas -, senão um levantamento menos incisivo sobre dificuldades e possibilidades. $\mathrm{O}$ capítulo correspondente à integração sistêmica, por outro lado, parece ser o que mais incorpora aspecto propositivo.

Fragmentação, constitucionalização, unidade e coerência são percepções sobre o direito internacional considerado em sua generalidade. Dificilmente se poderá, por isso, produzir um estudo que assimile todos os contornos dessas questões: inevitavelmente tal estudo implicará uma escolha de enfoque. Nesse passo, o relatório fez uma escolha clara de abordagem, centrando seus esforços no aspecto substantivo da fragmentação do direito internacional, o que significou ao relatório a análise de desenvolvimentos normativos os quais conduzem a um possível conflito de normas, como as consagradas dicotomias entre norma especial e geral, posterior e anterior, superior e inferior; além de contemplar um mecanismo interpretativo entendido como fator integrador das relações normativas. $\mathrm{O}$ relatório se ocupa de aliar considerações teóricas à análise de como tais dicotomias e a integração sistêmica foram assimiladas pelos tribunais internacionais a partir de suas decisões. Como consequência, grande parte das críticas feitas ao relatório se dá sobre tal escolha, sobretudo a exclusão da dimensão institucional do fenômeno da fragmentação.

Nesse prumo, críticas como a de Christian LEATHLEY e Nele MATZ-LÜCK foram reproduzidas neste trabalho. Para eles, o problema da fragmentação é manifestamente institucional, a solucionar-se a partir da estrutura organizacional e alocação de autoridades. LEATHLEY, segundo o qual inevitavelmente a Comissão de Direito Internacional terá de tratar futuramente do aspecto institucional do problema, aborda-o a partir da proposta de hierarquização de tribunais internacionais, a conferir-se à Corte Internacional de Justiça autoridade superior a partir de elementos já constantes do sistema jurídico internacional: o dever de integração sistêmica, a prioridade da Carta das Nações Unidas estabelecida em seu artigo 103, o fato de a Corte Internacional de Justiça ter sido criada pela Carta, a referência a esta prioridade feita pelo artigo 30 da Convenção de Viena sobre Direito dos Tratados de $1969^{423}$. Por outro lado, MATZ-LÜCK entende que, conquanto a abordagem institucional implique análise sobre autoridade para decidir qual norma a ser aplicada, esta seria indispensável ao estudo da fragmentação, já que a integração de autoridades teria o condão

${ }^{423}$ LEATHLEY, Christian; Op. Cit. Nota 109. 
de promover a desejada integração substantiva ${ }^{424}$. Outro ponto de vista também relevante a esta crítica foi a de Maksmylian DEL MAR, para quem, ao não tratar conflitos jurisprudenciais como tipo genuíno de fragmentação do direito internacional, o relatório erroneamente faz crer que normas têm existência separada de sua aplicação e argumenta, por isso, que o entendimento sobre raciocínio jurídico foi reduzido. Seu propósito foi, ao demonstrar contradições epistêmicas no relatório, oferecer meios alternativos de racionalidade jurídica, os quais levem em conta a realidade dos tribunais. O autor, inclusive, sugere uma nova agenda à CDI, a qual reveja o relatório tomando por base a inextricabilidade entre normas e sua adaptabilidade factual em contextos institucionais específicos ${ }^{425}$. Seria necessário produzir estudo empírico.

As críticas não se resumiram à exclusão do aspecto institucional. O relatório poderia tocar em tantos outros pontos, normativos mesmo, que teriam relevância para o exame da fragmentação do direito internacional. O princípio da boa-fé, por exemplo, poderia ser abordado como limitação ao poder dos estados em se desviarem de normas internacionalmente estabelecidas a partir da formulação de novas normas; Adamantia RACHOVITSA manifesta surpresa ao ver que no debate acerca das dificuldades sobrevindas da expansão e diversificação do direito internacional - fragmentação - não se tenha discutido a cláusula da proteção mais favorável aos direitos humanos, já que para ela esta cláusula aliviaria bastante tais dificuldades ${ }^{426}$. Talvez o estudo de como as fontes do direito internacional se relacionam com o tema seria igualmente apropriado.

O capítulo do relatório sobre lex specialis e regimes autônomos reúne observações as quais se relacionam com todo o tema da fragmentação do direito internacional. Note-se, por exemplo, as três possibilidades de conflito inclusas neste capítulo: divergência jurisprudencial, exceção ao direito geral, ou duas normas que se apresentam como especiais. As duas últimas se relacionam com o critério da especialidade, mas a primeira não necessariamente. Como esta abordagem é tratada neste capítulo, as críticas relativas à exclusão do aspecto institucional foram reproduzidas igualmente no capítulo correspondente. Também foram analisados debates que se centraram no diálogo entre órgãos judicantes do direito internacional: esta perspectiva não pode ser tida como impacto do

\footnotetext{
${ }^{424}$ MATZ-LÜCK, Nele; Op. Cit. Nota 111.

${ }^{425}$ DEL MAR, Maksymilian; Op. Cit. Nota 104; pp. 38 - 59.

${ }^{426}$ RACHOVITSA, Adamantia; Treaty Clause and Fragmentation of International Law: Appliying the More Favorable Protection Clause in Human Rights; Human Rights Law Review; Vol. 16; 2016; pp. 78 e 79.
} 
relatório propriamente, mesmo porque este se abstivera de tecer maiores considerações a respeito do tema, mas foi importante esclarecer que esta discussão permanece viva e suscita interesse sob diversos ângulos, seja para analisar eventuais mecanismos de diálogo - como fez a Sociedade Americana de Direito Internacional -, seja para proclamar a necessidade de análise empírica sobre a realidade dos tribunais - como defendeu o professor George Rodrigo Bandeira GALINDO. A dificuldade encontrada pelo relatório, no aspecto institucional, é claramente a ausência de hierarquia entre instituições, da qual resultam incertezas jurídicas. Demonstrou-se, neste trabalho, ademais, que o ideal de hierarquia institucional, de modo que a Corte Internacional de Justiça venha a assumir o topo de dita hierarquia, ainda permanece como proposta de alguns estudiosos. De todo modo, ao longo desses dez anos decorridos da conclusão do relatório, observa-se que o debate não se resume a saber se o aumento do número de órgãos é nocivo ou não à unidade do direito internacional, senão houve proposições materiais e epistêmicas sobre o diálogo entre órgãos.

Sobre os aspectos técnicos de aplicabilidade de lex specialis não houve divergências fundamentais. Basicamente, o relatório sustenta que a máxima da preferência pela norma especial é relativa, dependerá do contexto no qual ambas as normas são invocadas e que a interpretação deve evitar o conflito normativo, de modo que o critério se aplique somente caso seja impossível a interpretação harmoniosa, conjunta. Sempre que se possa ler uma norma especial como sendo a aplicação de uma norma geral, a segunda deve ser entendida como contida na primeira. Por isso, o relatório adota uma postura crítica à jurisprudência da Corte Europeia de Direitos Humanos a qual, conforme indicam alguns casos, procura selecionar uma norma a ser aplicada e excluir outras possíveis, em vez de relacioná-las.

O estudo de lex specialis no direito internacional, porém, suscita questões sobre interseções temáticas. Relevante foi a opinião de Bill BOWRING sobre a relação entre direitos humanos e direito humanitário, bem como sua crítica às decisões da CIJ acerca da não cessação dos direitos humanos em caso de conflito armado, de modo que as disposições do direito humanitário sejam leges speciales em relação aos direitos humanos. Para ele, circunstâncias especiais do caso invocam uma ou outra categoria de normas. Ponderado foi, inclusive, se há benefícios na descrição de um "ramo" do direito internacional como lex specialis em relação a outro e particularmente no caso dos direitos humanos os quais, dado seu conteúdo eminentemente axiológico, poderiam ser tidos não como norma geral, mas como pilar do sistema jurídico internacional, de modo que condicione toda sua 
inteligibilidade. Neste caso seria possível conceber os direitos humanos tal qual os entende Pedro de Abreu DALLARI, para quem eles constituem mais do que especialidade temática senão verdadeiro fator estruturante do sistema jurídico internacional ${ }^{427}$.

Sobre a relação entre geral e especial, o relatório foi objeto de críticas. Anastasios GOURGOURINIS sustentou que o relatório não ofereceu definição precisa do que seria geral e especial. Para ele, a solução para este impasse seria distinguir normas pelo seu alcance, de modo que normas vinculantes a todos os membros da sociedade internacional devem ser tidas como gerais ${ }^{428}$. Para DEL MAR, o direito geral só poderia ser identificado por meio de estudo pragmático ${ }^{429}$. Por outro lado, Melissa Zekiye CALTI entende que o direito internacional, por sua organização em regimes, não permite distinguir o geral do especial $^{430}$. A solução encontrada pelo relatório para este impasse foi sustentar que o geral e o especial têm caráter relacional: um só pode ser identificado em relação ao outro, o que dependerá do contexto no qual as normas serão invocadas.

Por outro lado, quando o relatório se põe a analisar a permissibilidade da formulação de uma norma especial, este se depara com um dos atributos o qual pode ser tido como dificuldade a acarretar fragmentação: o caráter dispositivo de grande parte do direito internacional. É evidente que a ausência de ampla e rígida hierarquia normativa no direito internacional é frequentemente apontada como condição problemática às unidade e coerência do direito internacional, e essa percepção permeia toda a elaboração do relatório. De todo modo, o relatório teve o mérito de apontar que a permissibilidade da elaboração de norma especial depende se a norma a ser preterida corresponde a jus cogens, obrigação erga omnes, ou se meramente a nova norma frustra expectativas de terceiros estados. A observância ao objeto e propósito do tratado o qual se pretende preterir deve ser, adicionalmente, levada em consideração. O relatório igualmente aponta que o critério da especialidade não guarda uma relação clara com o da posterioridade à luz da CVDT. Sobre todas essas afirmações, não foram encontradas contraposições posteriores.

Com efeito, maior controvérsia recai sobre a capacidade de os critérios de preferência normativa efetivamente solucionarem os problemas decorrentes da diversificação e expansão do direito internacional, sobretudo por conta de sua organização no que se

\footnotetext{
${ }^{427}$ DALLARI, Pedro de A.; Op. Cit. Nota 83.

${ }^{428}$ GOURGOURINIS, Anastasios; Op. Cit. Nota 201.

${ }^{429}$ DEL MAR, Maksymilian; Op. Cit. Nota 104.

${ }^{430}$ CALTI, Melissa Zekiye; Op. Cit. Nota 204.
} 
convencionou chamar de 'regimes autônomos'. Há posicionamentos de preferência por critérios em detrimento de outros, o que certamente se justifica na possibilidade de eles reverberarem na estabilidade do sistema jurídico internacional. Anthony AUST ${ }^{431}$, Bruno SIMMA e Dirk PULKOSKI ${ }^{432}$ depositam no critério da especialidade a virtude de efetivamente resolver conflitos e assegurar o equilíbrio das relações internacionais. Por outro lado, a organização do direito internacional em categorizações temáticas causa ceticismo em alguns estudiosos - como GHOURI - sobre a capacidade do critério da especialidade promover a consistência do direito internacional ${ }^{433}$. O relatório toma, igualmente, a organização do direito internacional em regimes como dificuldade à aplicação do critério da especialidade, sobretudo quando aponta que as normas em conflito devem tratar do "mesmo assunto", visto que obrigações são incluídas em distintas categorizações temáticas e afetam umas às outras, sem que propriamente se possa dizer que versam sobre um "mesmo assunto".

A questão dos regimes autônomos, por seu turno, suscita intensa divergência de entendimento, desde sua definição. O relatório encontrou três possíveis sentidos para a expressão: conjunto de normas secundárias, conjunto de normas primárias e secundárias inter-relacionadas, e um ramo de especialização funcional que contenha normas próprias de administração, terminação e interpretação. O primeiro sentido no qual a expressão foi empregada, no caso "S.S. Winbledon", fora tida pelo relatório como ocasional, por tratar-se de uma norma singular especial. Bruno SIMMA e Dirk PULKOWSKI ${ }^{434}$, seguidos por Anastasios GOURGOURINIS, entendem que a definição de regimes autônomos se dá a partir de subsistemas que contenham normas secundárias, de modo que não se recorra ao sistema geral de responsabilidade internacional do estado em caso de violação às normas primárias as quais as normas secundárias específicas prometem assegurar. Para GOURGOURINIS o abandono da dicotomia entre normas primárias e secundárias para fins de definição e operação de regimes foi um erro do relatório ${ }^{435}$; como contraponto, para George Rodrigo Bandeira GALINDO e Loussia Penha Musse FELIX houve acerto, por ter o relatório permitido que os estudiosos do direito internacional entendam que lidam com racionalidades sociais em constante colisão ${ }^{436}$. Nota-se, a partir disso, que o termo 'regimes autônomos' tanto pode ser empregado como tendo um valor normativo em si, por meio do

\footnotetext{
${ }^{431}$ AUST, Anthony; Op. Cit. Nota 146.

${ }^{432}$ SIMMA, Bruno; PULKOSKI, Dirk; Op. Cit. Nota 125.

${ }^{433}$ GHOURI, Ali Ahmad; Op. Cit. Nota 116.

${ }^{434}$ SIMMA, Bruno; PULKOSKI, Dirk; Op. Cit. Nota 125.

${ }^{435}$ GOURGOURINIS, Anastasios; Op. Cit. Nota 201.

${ }^{436}$ GALINDO, George Rodrigo Bandeira; FELIX, Loussia Penha Musse; Op. Cit. Nota 152.
} 
qual se analisa a potencial aplicabilidade de outras normas sobre responsabilidade internacional que não estejam contidas no próprio regime; como pode ser empregado com abordagem sociológica para descrição do funcionamento da realidade social global e seu direito subjacente. De todo modo, também houve argumentos de que estudos empíricos e multidisciplinares devem ser produzidos para identificação do que sejam "regimes autônomos"437.

Ao tratar das condições para estabelecimento de um "regime autônomo", o relatório concebe o que se pode entender como uma forte defesa do direito internacional como sendo um sistema jurídico. Além de esclarecer restrições aos regimes autônomos - aquelas impostas à formulação de normas especiais -, e o recurso ao direito internacional geral em caso de lacuna, o relatório levanta uma série de casos em diferentes domínios nos quais os órgãos judicantes extraíram de conceitos jurídicos pertencentes ao direito internacional geral razões para a interpretação dos instrumentos os quais têm atribuição primária de aplicar. Demonstrou-se que os regimes autônomos não possuem normas específicas sobre conteúdos como "estado", “jurisdição", entre outros. O estudo ganha adeptos como Regis Yann $\mathrm{SIMO}^{438}$, a procurar demonstrar que o completo isolamento de conteúdos jurídicos organizados em categorias temáticas específicas inexiste. No entanto, se o relatório enfatiza e levanta casos em que houve relação de normas, e, por exemplo, no caso do direito do comércio internacional, produz tese jurídica a qual autoriza a aplicação da CVDT e, como consequência, habilita a aplicação de quaisquer normas internacionais de relevância; o relatório igualmente reconhece que isso não exclui existir um 'ethos' da OMC: novamente, o relatório parece ponderar a existência de racionalidades sociais especializadas as quais se chocam em casos específicos. O reconhecimento de racionalidades sociais - 'ethos' que inspiram os diferentes regimes - parece moderar a defesa do relatório do direito internacional enquanto sistema. Possivelmente, seja esta uma "dificuldade", encontrada pelo relatório, decorrente da expansão e diversificação do direito internacional.

No tocante à discussão sobre regionalismo, o relatório limita-se a indicar que sistemas jurídicos regionais devem obedecer a mesma lógica dos regimes autônomos, jamais constituindo-se como sistemas isolados. O relatório sustenta, igualmente, que o desenvolvimento de ditos sistemas pode vir a carrear os propósitos estabelecidos pelo direito internacional geral. Os argumentos do relatório foram relacionados a outros escritos os quais

\footnotetext{
${ }^{437}$ GALINDO, George Rodrigo Bandeira; Op. Cit Nota 81.

${ }^{438}$ SIMO, Regis Yann; Op. Cit. Nota 185.
} 
analisam a paradoxal relação entre direito geral e local: no campo comercial, por exemplo, alguns posicionamentos indicam prejuízos ao sistema multilateral, ao mesmo tempo que a flexibilidade e a sensibilidade a condições particulares de seus membros podem ter efeitos benéficos para o almejado fim a restrições comerciais. Alguns expedientes foram tidos como gozando de especial importância: a cooperação e os diferentes níveis de participação de membros no sistema de comércio, a cláusula da nação mais favorecida e o mecanismo de transparência sobre acordos regionais o qual o sistema multilateral conta. Permanece, segundo se conclui da participação de Gabrielle MARCEAU em debate promovido pela ASIL, a preocupação com a alocação de autoridades no direito internacional, a qual a autora articulou em atenção ao Caso das Restrições às Bebidas Açucaradas entre o México e os Estados Unidos da América, no qual a despeito da existência de normas regionais que seriam relevantes ao caso, a contenda foi decidida pelo sistema multilateral da $\mathrm{OMC}^{439}$. Ao longo desses dez anos de conclusão do relatório, outros escritos também se ocuparam de tratar da relação entre direito regional e geral sobre temas específicos, como foi a preocupação de Makus G. PUDER sobre se o direito regional poderia ser considerado "boa notícia" ao direito ambiental: o princípio da precaução, por exemplo, deve ser visto como vinculante no direito europeu; embora possa ser visto como não vinculante no sistema de direito internacional geral. Mas, a partir do caso da usina de MOX, o autor observa que o direito europeu só será benefício ao ambiente caso a integração europeia assim o faça com que seja ${ }^{440}$.

Pelo que se observa, não houve profunda contestação sobre as observações do relatório acerca do regionalismo. Talvez porque tais observações acabem por simplesmente submeter o regionalismo aos mesmo termos que toda a discussão sobre lex specialis e regimes autônomos, não desenvolvendo questionamentos exclusivos ao tema. Há quem entenda que as impressões do relatório, sobre regionalismo, sejam limitadas demais.

Como dito, no capítulo correspondente a lex specialis e regimes autônomos, o relatório lança mão de argumentos os quais denotam forte senso do direito internacional enquanto sistema. Tal constatação fica ainda mais evidente ao ler sua conclusão, tendo em vista que o relatório sustenta que os regimes estão vinculados ao direito internacional geral, que aqueles extraem sua força vinculante deste, que a validade normativa dos regimes é absorvida dos princípios gerais do direito internacional, além de o direito internacional geral

\footnotetext{
${ }^{439}$ MARCEAU, Gabrielle; Op. Cit. Nota 221.

${ }^{440}$ PUDER, Markus G.; Op. Cit Nota 223.
} 
ser aplicado em caso de lacuna ou falha do regime, bem como orienta sua interpretação; chega a defender, aliás, que o direito internacional geral controla a aplicação dos regimes, determinando qual regime deve prevalecer, ou, ao menos, estabelecendo consequências jurídicas pela escolha de um ou outro regime.

Em sua discussão sobre tratados sucessivos e critério da posterioridade, o relatório demonstra que há dificuldades na aplicação do critério, tal qual previsto pela CVDT. A CVDT não esclareceria o momento que o tratado deve ser considerado anterior ou posterior, tampouco esclareceria como este deve lidar com a máxima da especialidade. $\mathrm{O}$ aspecto horizontal das normas de direito internacional e o fato de ratificação a um tratado depender da aceitação do estado parecem ter sido lembrados pelo relatório ao vislumbrar uma possibilidade que colocaria intensas dúvidas à relação entre normas sucessivas: se for considerada a ratificação como termo para aplicação do critério da posterioridade; e caso uma parte, em eventual litígio, tenha ratificado um e outro tratado, ao que a parte contrária os tenha ratificado na ordem inversa, esta situação se torna insolúvel. Novamente, o relatório parece ter se deparado com a horizontalidade do direito internacional como "dificuldade" decorrente sua diversificação e expansão: a ausência de um processo legislativo centralizado traria consequências dificultosas à relação entre normas em relação ao tempo.

O relatório postula a não automaticidade da aplicação do critério da posterioridade, na medida em que se analise se as normas sucessivas podem ter aplicação sob o princípio da harmonização; devendo-se igualmente apreciar se a substituição do padrão normativo fora intencionada pelas partes; assim como, em caso de litígio, entre o critério da especialidade e posterioridade, um órgão pode decidir qual elemento seria mais decisivo para a solução do litígio, assim como pode decidir pela não aplicação de quaisquer deles. Por certo que, assim como a norma especial, a norma derrogadora posterior necessariamente deve gozar do mesmo status normativo que a norma derrogada.

Ademais, o relatório pontua que há situações de não identidade entre as partes do tratado anterior e posterior, de modo que subsistam diferentes direitos dependendo das partes ou conjunto delas. Neste ponto, foi relembrada a visão de JENKS segundo a qual o fato de nem todos os estados participarem da revisão de tratados poderia se traduzir em inconsistências sistêmicas no direito internacional. Além disso, o relatório afirma que o critério da posterioridade tem sido aplicado em contexto complexo de conjuntos normativos: tais conjuntos podem ser arbitrariamente categorizados de modo que, embora suas 
disposições prevejam obrigações que impactam obrigações contidas em outro instrumento, não sejam considerados como tratando do "mesmo assunto". Talvez o critério da posterioridade dependa de certa linearidade conceitual nas previsões dos tratados sucessivos.

O relatório apura, inclusive, que ao longo da história do estudo do direito internacional houve manifesta preferência pela norma anterior ou posterior. $\mathrm{O}$ direito internacional parece oscilar, conforme se colocou, entre o entendimento de que uma nova norma corresponda a um padrão normativo a substituir o anterior ou a uma violação ao primeiro. Para todas essas questões, o relatório defende a apropriada distinção entre obrigações, reconhecendo-se obrigações "integrais" e "interdependentes" como forma de atribuir consistência ao direito internacional.

Neste ponto, não houve críticas à abordagem do relatório, senão certo ceticismo sobre a capacidade de o critério da posterioridade promover coerência à relação entre normas, como foram os posicionamentos, tratados neste trabalho, de Ahmad Ali GHOURI, bem como de MICHAELS e PAUWELYN ${ }^{441}$. Para GHOURI, a relação entre normas sucessivas, já que não tratada em termos de validade jurídica, se dá pelo princípio da decisão política, de modo que discricionariamente o estado pode escolher qual tratado cumprir e, nestes termos, o critério seria completamente incapaz de solucionar conflitos normativos ${ }^{442}$.

Contudo, mais controvertida é a questão sobre o que pode ser considerado como o "mesmo assunto", para fins de aplicação do critério da posterioridade. O relatório se filia à corrente a qual entende que duas normas tratam do "mesmo assunto" caso os direitos e obrigações nelas contidas não possam ser atendidos ou desfrutados simultaneamente de maneira integral. Não há exigência - como entenderia a vertente estrita - de que as normas se dirijam a uma mesma hipótese, com certa linearidade conceitual e contextual. Adarsh RAMANUJAN observa que o relatório adere a esta corrente ao denunciar a possível arbitrariedade na classificação de complexos normativos a partir de suas categorizações temáticas, e saúda a perspectiva do relatório ${ }^{443}$. Dada a organização dos conteúdos jurídicos internacionais em categorias de operação técnica específicas, a visão estrita sobre o que seja “mesmo assunto" praticamente invalidaria a aplicação do critério. Por outro lado, a extensão do que possa ser tido como "mesmo assunto" pode acarretar em dispensa de importantes

\footnotetext{
${ }^{441}$ PAUWELYN, Joost; MICHEALS, Ralf; Op. Cit. Nota 146.

${ }^{442}$ GHOURI, Ali Ahmad; Op. Cit. Nota 117.

${ }^{443}$ RAMANUJAN, Adarsh; Op. Cit Nota 256.
} 
normas internacionais. O relatório parece amenizar este risco ao proclamar a relatividade da aplicação do critério da posterioridade, condicionando-o a outros fatores, como a intenção das partes, o atendimento aos objeto e finalidade dos tratados, defendendo a apropriada distinção entre obrigações "integrais" e "interdependentes", bem como ao sustentar que, entre norma anterior e posterior, há uma relativa prioridade pela última, quando as partes sejam idênticas, de modo que sua relação não se conceba em termos de validade jurídica.

Sobre cláusulas especiais que cuidam da relação com outros tratados, não foram identificadas objeções aos termos do relatório, senão a declaração de suas pertinências em um terreno de imensas dúvidas. Estas ajudam a esclarecer como os tratados devem ser entendidos em relação uns aos outros. Apontado foi, por outro lado, a opinião de PAUWELYN e MICHAELS, no sentido de que os tratados, quando anunciam sua prevalência em relação aos outros, demonstram sua não isenção frente a outros regimes. Para os autores, é o que se dá no artigo 103 da Carta das Nações Unidas ${ }^{444}$.

No tocante à modificação de tratados multilaterais por acordos inter se, o relatório faz apelo à preservação dos objeto e propósito do tratado original, sob inteligência do artigo 41 da CVDT. Apesar deste parâmetro, este entende que, à semelhança das reservas a tratados, os acordos inter se acabam por acarretar a relações jurídicas distintas. Entretanto, a discussão sobre modificação de tratados contemplou estudo sobre a não-proliferação de armas de destruição em massa, tal qual tratada por Malgosia FITZMAURICE e Panos MERKOURIS, os quais ponderam a possibilidade de regimes especiais estabelecerem normas específicas sobre modificação e emenda a tratados, de modo que a CVDT não se aplique $^{445}$. A possibilidade de derrogação da CVDT, pelo que se apurou, não foi objeção aos argumentos do relatório. Sua possibilidade pode vir a relativizar a confiança depositada pelo relatório à CVDT como referência básica para a coerência sistêmica do direito internacional.

Já sobre seu estudo de relações de maior importância normativa, jus cogens, obrigações erga omnes e o artigo 103 da Carta das Nações Unidas, novamente o aspecto horizontal e dispositivo do direito internacional foi salientado. Sobre o artigo 103 da Carta das Nações Unidas, esclareceu-se a visão de PAUWELYN e MICHAELS ${ }^{446}$, os quais situam o dispositivo no mesmo plano que outras normas contidas em tratados as quais declaram a

\footnotetext{
${ }^{444}$ PAUWELYN, Joost; MICHAELS, Ralf; Op. Cit. Nota 146.

445 JOYNER, Daniel H.; ROSCINI, Marco (Ed.); Op. Cit. Nota 295.

${ }^{446}$ PAUWELYN, Joost; MICHAELS, Ralf; Op. Cit. Nota 146.
} 
superioridade de suas disposições. Para outros autores - AUST $^{447}$, MILANOVIC $^{448}$-, o artigo 103 revela o caráter inigualável, em termos de importância, da Carta das Nações Unidas.

Com efeito, especificamente sobre o artigo 103, o relatório aponta que há dificuldades em saber se sua prevalência abrange não membros das Nações Unidas, ou mesmo se ela se impõe a todas as fontes do direito internacional. Também sobre o dispositivo, esclareceu-se que este tem uma especial relação com o tema das sobreposições jurisprudenciais, em particular a afamada rivalidade de entendimentos entre a Corte Internacional de Justiça e o Tribunal Penal Internacional para a Antiga Iugoslávia, visto que a prevalência do artigo 103 da Carta das Nações Unidas se estende às resoluções do Conselho de Segurança e, ao que a CIJ foi criada pela Carta, o Tribunal foi criado por resolução do Conselho. Interessantemente, CANNIZZARO ${ }^{449}$ se adianta ao problema, ao defender que o Conselho de Segurança não tivera a intenção de conferir autoridade superior ao Tribunal sobre a interpretação da Convenção para Prevenção e Repressão ao Crime de Genocídio. De todo modo, cumpre esclarecer que a CIJ, no Caso Relativo à Aplicação da Convenção para Prevenção e Repressão ao Crime de Genocídio, abordou a relação entre órgãos e suas respectivas jurisprudências, não sob o ponto de vista da autoridade superior para decidir, mas a partir da delimitação da esfera de jurisdição do Tribunal, o qual não poderia ser persuasivo sobre o julgamento de estados - sobre outros pontos sim - já que a atribuição do Tribunal é julgar indivíduos.

Sobre jus cogens, sua capacidade de solucionar conflitos normativos é geralmente referida como dificultosa, já que, como se demonstrou, para grande parte dos estudiosos de direito internacional, seu conteúdo é extremamente limitado (MILANOVIC ${ }^{450}$ ), ou como indicou o relatório não há uma lista de normas imperativas que se imponha com autoridade. Para alguns autores, o conteúdo de jus cogens é "pouco e opaco" (SIMMA e PULKOWSKI $\left.^{451}\right)$.

Por sua vez, o estudo do relatório sobre as obrigações erga omnes contém um único foco de controvérsia: o relatório diferencia jus cogens de obrigações erga omnes, por ser jus

\footnotetext{
${ }^{447}$ AUST, Anthony; Op. Cit. Nota 147.

${ }^{448}$ MILANOVIC, Marko; Op. Cit. Nota 315.

${ }^{449}$ CANNIZZARO, Enzo; Op. Cit. Nota 328.

${ }^{450}$ MILANOVIC, Marko; Op. Cit. Nota. 315.

${ }^{451}$ SIMMA, Bruno; PULKOSKI, Dirk; Op. Cit. Nota 125.
} 
cogens questão de importância - expressam-se valores jurídicos mais fortes - e as obrigações erga omnes questão de abrangência - envolve maior número de participantes. Vassilis P. TZEVELEKOS criticou o relatório por apresentar visão conservadora sobre o tema, uma vez que o aspecto procedimental - autorizando qualquer estado a reclamar o cumprimento das obrigações erga omnes - só pode ser explicado por aspecto substantivo, entendendo-se que tais obrigações incorporam valores considerados de maior importância no sistema jurídico internacional $^{452}$.

Por outro lado, o estudo a respeito do mecanismo de integração sistêmica do relatório apresenta alguns interessantes e pertinentes focos de discussão. A começar que nos debates na Comissão, convencionou-se não referir ao mecanismo como sendo um "princípio", preferindo-se a expressão "objetivo". Curiosamente, a versão final do relatório faz menção a "princípio da integração sistêmica". Na primeira discussão do grupo de estudo sobre integração sistêmica, cuja análise inicial foi produzida por William MANSFIELD, entendeuse que o dispositivo da CVDT não teria o condão de solucionar os problemas decorrentes da fragmentação, uma vez que, sendo um recurso eminentemente interpretativo, este só se aplicaria caso um tratado apresentasse qualquer lacuna ou ambiguidade. Certamente, o grupo superou este entendimento, ao verificar que as possibilidades de interpretação previstas no artigo 31 da CVDT diferenciam-se das previstas no artigo 32: o primeiro trata da interpretação de tratados e, entre outros meios, anuncia a possibilidade de considerar qualquer regra relevante e aplicável entre as partes; o segundo trata de meios suplementares de interpretação, caso tenha resultado obscuridade ou ambiguidade, ou ainda se o resultado é absurdo ou desarrazoado. Nota-se que os meios previstos no artigo 31 da CVDT são formas primárias de interpretação de tratados.

Entretanto, remanesce a dúvida sobre se a integração sistêmica serve à interpretação dos termos de um tratado ou de um dispositivo particular, identificando seu sentido ao relacioná-los a outros conteúdos que sejam relevantes e aplicáveis às partes, ou se é um dever jurídico de aplicação e interpretação do direito internacional como um todo. Ao tratar o mecanismo por "princípio", bem como ao sustentar que o dispositivo não esclarece qual o peso a ser conferido às outras regras relevantes e aplicáveis às partes para fins de oportunizar o sopesamento entre normas, o relatório faz clara opção pelo segundo sentido: seria um dever jurídico de aplicação de todas as normas que se relacionam ao caso, inclusive indicando qual

452 TZEVELEKOS; Vassilis P.; Op. Cit. Nota 179. 
o peso a ser atribuído a cada qual. Esta opção fica clara ao que o relatório argumenta que o dispositivo da integração sistêmica aponta para a necessidade de se compreender o ambiente normativo como um todo, absorvendo deste objetivos compreensíveis e coerentes, inclusive identificando conteúdos os quais devam ser tidos por prioritários. Esta perspectiva seria objeto de reações.

Vassilis P. TZEVELEKOS criticou o relatório por ter deixado de compreender o artigo 31 (3) (c) como método interpretativo, mas como verdadeiro princípio jurídico o qual impõe um dever de consideração de todo o ambiente normativo. $\mathrm{O}$ autor indicou diversos usos ao dispositivo, pela Corte Europeia de Direitos Humanos, inclusive para fins de afirmar sua jurisdição - em alguns casos declinando-a -, ou com o fito de conferir interpretação extensiva aos direitos humanos. A consideração do ambiente normativo como um todo é um benefício apenas secundário, para o autor ${ }^{453}$.

Essa discussão, como bem se demonstrou, leva ainda a um segundo questionamento: se a integração sistêmica pode ser entendida como correspondente ou mesmo como viabilizadora da técnica de balanceamento. Apontou-se, neste sentido, a posição de Anne VAN AAKEN, para quem a integração sistêmica deve contemplar princípios gerais do direito e princípios de direito internacional, com o fito de oportunizar esta técnica a qual é o segundo meio mais eficaz de promoção da coerência sistêmica, perdendo apenas para uma rígida hierarquia de normas. A autora diferenciou "integração sistêmica" da "técnica de balanceamento", ao sustentar que a primeira indica "quais" normas devem ser consideradas, ao que a segunda trata de "como" devem ser consideradas ${ }^{454}$. Guilherme DEL NEGRO, por seu turno, criticou a abordagem do relatório por confundir integração sistêmica com balanceamento: para ele, o balanceamento não é sequer método interpretativo, a ser empregado caso, mesmo após a interpretação, permaneça o conflito, de modo que obrigue o intérprete a fazer uma escolha entre elementos válidos do sistema sobre os quais se deva definir prioridades ${ }^{455}$.

No transcurso desses dez anos, houve algumas revisões de posicionamentos. Joost PAUWELYN, a quem o relatório confiara para dizer que os estados, embora possam derrogar parte ou todo - ressalvado jus cogens - o direito internacional, mas jamais se apartar

\footnotetext{
453 Idem.

${ }^{454}$ VAN AAKEN, Anne; Op. Cit. Nota 379.

${ }^{455}$ DEL NEGRO, Guilherme; Op. Cit. Nota 413.
} 
do sistema de direito internacional ${ }^{456}$, escreveu, juntamente com Ralf MICHAELS, artigo sustentando que nem todo o direito internacional pode ser tido como sistema, de modo que a solução de conflitos normativos seja bem menos importante do que acreditou a CDI: bastaria que o relatório deduzisse que, nos campos onde o direito internacional pode ser entendido como sistema, adotam-se os critérios de derrogabilidade normativa; no entanto, em casos que tal entendimento não seja possível, adotam-se soluções próprias para relações inter-sistêmicas, como são as normas de direito internacional privado ${ }^{457}$.

Pode-se dizer que o relatório produziu três tipos de impacto: (1) uma vez que ele aborda questões conceituais e aplicação de dispositivos centrais ao debate da coerência sistêmica do direito internacional, seu estudo é referido por autores os quais, procurando produzir literatura sistematizadora sobre os institutos tratados pelo relatório, coletam argumentos por ele articulados. Embora não tenha a intenção direta de constituir estudo dogmático, senão indicar dificuldades e edificar um guia para lidar com a fragmentação, este pode ser analisado para esses fins. Neste primeiro sentido o impacto do relatório é relativo: no caso do estudo ao direito dos tratados, pode-se recorrer ao relatório como fonte extremamente instrutiva sobre institutos previstos na CVDT, sem que tal passagem seja obrigatória. Foi o que ocorreu com a obra brasileira vocacionada a comentar a CVDT, a qual o relatório foi mencionado nos comentários a certos dispositivos, não recebendo, porém, atenção em relação a outros dos quais o relatório também tratou ${ }^{458}$; (2) diante de toda a discussão a respeito de fragmentação e coerência sistêmica no direito internacional, há um louvável esforço de busca por interseções temáticas, de modo que estudiosos, escrevendo sobre domínios específicos de operação jurídica do direito internacional, procuram relacioná-los a outros conteúdos de direito internacional. O relatório, neste caso, recebe menções ao se entender que a compartimentação dos "ramos" do direito internacional deva ser rebatida com análises associativas entre tais direcionamentos, sob pena de haver fragmentação. Igualmente, neste segundo sentido, o impacto é ocasional e indireto, já que é possível entender que a busca pelo ponto de contato entre categorias jurídicas não tenha sido inaugurado pelo relatório, embora seu estudo tenha se tornado pertinente, neste ponto, após sua conclusão; (3) o estudo contido no relatório, por fim, impacta, como não poderia deixar de ser, na discussão sobre constitucionalismo, unidade, fragmentação, coerência sistêmica e solução de conflitos normativos. Neste ponto, seu estudo se dá para discussão dos próprios

\footnotetext{
${ }^{456}$ PAUWELYN, Joost; Op. Cit. Nota 195.

${ }^{457}$ MICHAELS, Ralf; PAUWELYN, Joost; Op. Cit Nota 146; p. 375.

${ }^{458}$ SALIBA, Aziz Tuffi (org.); Op. Cit. Nota 300.
} 
temas aos quais o relatório se dedica, e estudiosos o menciona, seja para criticá-lo, seja para extrair dos termos do relatório a racionalidade de suas abordagens e desenvolvimento teórico.

Porém, dificilmente se pode dizer que houve alteração das circunstâncias as quais desencadearam o debate sobre unidade, fragmentação ou coerência do direito internacional. Sean D. MURPHY avalia o impacto do relatório sete anos após sua conclusão. Diz que este fora amplamente citado por estudiosos do direito internacional, e também muito criticado, sobretudo por ter excluído a questão da relação entre instituições internacionais de sua análise. Outros teriam criticado o relatório por tentar promover 'integração sistêmica' entre um tratado contemporâneo e um antigo - como as tentativas de interseção entre o direito humanitário e direitos humanos, as quais no presente trabalho se fizeram representar pela a opinião de Bill BOWRING -, além de críticas pontuais a certas afirmações. O autor salienta, inclusive, os numerosos esforços de esclarecimento da interseção entre "ramos" do direito internacional, com particular impacto sobre os estudos acerca dos direitos humanos, direito humanitário e direito dos investimentos estrangeiros. O relatório corresponde a uma fonte importante para o estudo de conflitos específicos, envolvendo o direito ambiental e direito do comércio internacional ${ }^{459}$.

A seguir, MURPHY faz indagação interessante: se o relatório constitui uma confirmação ou uma traição aos trabalhos de Martti KOSKENNIEMI. Sobre a identificação do relatório de antinomias, haveria afinidade com as percepções de KOSKENNIEMI sobre a pós-modernidade. Por outro lado, argumenta MURPHY, que a visão do relatório de que o direito internacional constitua um único sistema e não uma coleção aleatória de normas, além da impressão de que há graus maiores ou menores de hierarquia normativa, não apresenta correspondência nos trabalhos de KOSKENNIEMI, visto que em grande parte dos trabalhos deste há uma noção de que o direito internacional é um sistema sem hierarquias e, portanto, não oferece meios de solução de conflitos internos. Por exemplo, os conflitos envolvendo os direitos humanos não são meramente interpretativos na visão de KOSKENNIEMI, mas obedecem a inteligibilidade específica, sob pressupostos e valores próprios. Diz, ainda, em atenção ao trabalho de MICHAELS e PAUWELYN, que o relatório foca em conflitos entre

459 MURPHY, Sean D.; Deconstructing Fragmentation: Koskenniemi's 2006 ILC Project; Temple International \& Comparative Law Journal; Forthcoming; GWU Law School Public Law Research Paper $n^{\circ}$ 2013-109; 14 de Junho de 2013. 
normas e, assim, perde a oportunidade de estudar conflitos entre sistemas jurídicos, os quais seriam regulados por mecanismos próprios do direito internacional privado ${ }^{460}$.

Com efeito, MURPHY argumenta que o relatório deixou de abordar temas importantes ao conflito normativo, mormente técnicas de negociação, cooperação e coordenação. O relatório não seria propenso a tratar de competição entre interesses diversos que operam por meio dos diferentes regimes. Por outro lado, pudera o relatório abordar temas como a conveniência das competições jurisprudenciais, mas decidiu insistir na descrição do direito internacional público como um sistema coerente. Além disso, especificamente sobre a questão do regionalismo, o relatório não é satisfatório ao esclarecer o fenômeno e sua relação com a questão da fragmentação, apenas descrevendo-o como uma forma de lex specialis; o que não posiciona o regionalismo como um rico contexto cultural e normativo. Outro ponto de contraste, são as suspeitas de KOSKENNIEMI em relação ao desenvolvimento técnico o qual anima as diferentes esferas operacionais de normatividade no direito internacional. O relatório parece manter o discurso técnico-jurídico e se filiar à mentalidade gerencial ${ }^{461}$.

Esta é uma observação interessante de MURPHY. Talvez, o relatório não ofereça adesão ao pensamento de KOSKENNIEMI, por ter o relatório dado resposta extremamente técnica a um problema que, para KOSKENNIEMI, a técnica ajudou a criar.

Por fim, MURPHY questiona a importância do relatório para a codificação e sistematização do direito internacional público. Neste ponto, o relatório conclama maior atenção a normas que tratem de conflito normativo; faz importante diferenciação de relação de normas dentro de um regime ou entre regimes; indica que futuros trabalhos devem ser realizados para a compreensão do que seja direito internacional geral. Diz MURPHY que futuros relatórios são esperados: novos estudos sobre as questões tratadas pelo relatório, mas, espera o autor, que outros tópicos sejam abordados, incluindo conflitos de jurisdições ou a relação entre direito internacional e direito interno ${ }^{462}$.

Tomer BROUDE também avalia a atualidade do relatório após transcorridos sete anos de sua conclusão. Para ele, a única coisa interessante que ocorreu desde a conclusão do relatório foi o falecimento do debate acerca da fragmentação. Apesar de a fragmentação

\footnotetext{
${ }^{460}$ Idem; pp. $300-302$.

${ }^{461}$ Ibidem; pp. 302 e 303.

462 Ibidem; pp. $304-307$.
} 
ainda estar viva, aduz o autor, o fenômeno foi normalizado - aceito, como politicamente inevitável e interpretativamente manejável - e não considerado como potencial ameaça ao direito internacional enquanto sistema. Diz ele que agora fomos engorajados a parar de temer a fragmentação e passar a amá-la, ou mesmo pensar além dela ${ }^{463}$.

Se esta proposição estiver correta, o impacto do relatório teria sido esmorecer a efervescência do debate sobre fragmentação. Possivelmente, a discussão tenha se tornado mais complexa diante da densidade da argumentação do relatório. Neste caso, o que se põe como possibilidade é que a fragmentação tenha se tornado mais dificilmente demonstrável a partir do estudo do relatório, não porque este tenha recusado sua realidade, senão porque, agora, tornou-se mais problemática a demonstração do que seja, efetivamente, a fragmentação. Isso será verdade se a perspectiva do relatório, da fragmentação como dificuldades - e não impossibilidades - sobrevindas da expansão e diversificação do direito internacional, tenha sido extremamente convincente para que estudiosos possam continuar a abordar o fenômeno como um processo necessariamente negativo. Representativa desta proposição seja, certamente, a perspectiva da obra "Non-Proliferation Law As a Special Regime - A Contribution to Fragmentation Theory In Internacional Law". Ao introduzi-la, Daniel H. JOYNER e Marco ROSCINI, tomam a fragmentação como um risco, mas não à credibilidade e efetividade do direito internacional, senão um risco de aumento de conflitos normativos e incompatibilidades sistêmicas, abordagem esta ambasada no relatório. Ademais, os autores esclarecem que o próposito da obra é avaliar se o "direito de nãoproliferação" constitui um regime especial - proclamando que regimes autônomos não existem, pelas próprias razões do relatório - e em que medida se estende a especialidade. Para tanto, recorrer-se aos dispositivos da CVDT, inclusive para se compreender limitações ao direito dos estados em se desvincularem das normas vigentes sobre não-proliferação de armas de destruição em massa ${ }^{464}$. Trata-se de obra a qual adere os pressupostos e argumentos do relatório, trazendo-os à análise específica sobre as implicações ao direito de nãoproliferação.

Nesta linha, fragmentação ainda seria vista como um problema, mas não como um risco imposto à estabilidade do sistema jurídico internacional. Fragmentação seria dificuldade em se promover a coerência, e um certo dever da sociedade internacional de

${ }^{463}$ BROUDE, Tomer; Keep Calm and Carry On: Martti Koskenniemi and the Fragmentation of International Law; Temple International \& Comparative Law Journal; Vol. 27; n 2; 1 de maio de 2013.

${ }^{464}$ JOYNER, Daniel H.; ROSCINI, Marco (Ed.); Op. Cit. Nota 297; pp. 1 - 14. 
dispensar atenção às possibilidades de solução ou coordenação de conflitos normativos. Neste sentido, a observação de BROUDE sobre o impacto do relatório parece ser verdadeira.

O estudo do relatório, possivelmente, remete a dúvidas maiores: e se o direito internacional ao se ocupar de solucionar potenciais conflitos normativos e, em nome de sua coerência, acabar por dispensar conteúdos jurídicos os quais seriam vitais para preservação de interesses da humanidade? Ou mesmo, caso se possa associar unidade a conservação do estado das coisas e fragmentação - diversificação ou pluralismo - a possibilidade de transformação, por que a conservação é melhor do que transformação? Aliás, essas discussões todas, que reconhecidamente lidam com ideais do direito internacional, caso o estudioso ainda venha a analisar a conveniência de um ou outro ponto de vista, necessariamente este terá de explicitar se unidade, independententemente de suas implicações, é sempre um objetivo a ser perseguido; se coerência e certeza jurídica são virtuosas por sí só e independem de outros fatores; se pluralismo é benéfico ou prejudicial e o quê o faz ser um ou outro; se fragmentação deva mesmo ser assim assimilada e se será, independentemente de seus contornos, perniciosa para as relações jurídicas internacionais. Outra dúvida que se impõe é se por fragmentação se entende um processo em curso, ou se é um momento do direito internacional a ser superado pelos esforços de sistematização.

Ademais, o estudo do relatório enseja dúvidas sobre se, entre fragmentação e coerência, deva haver conclusões absolutas por um ou outro; ou se também suas percepções não podem possibilitar gradações, de modo que se conclua que o direito internacional seja mais ou menos fragmentado, mais ou menos coerente. E um raciocínio correlato, o qual emerge deste questionamento, poderia levar o estudioso a questionar se, no embate entre constitucionalização e fragmentação, os dois fenômenos serão necessariamente excludentes - ou o direito internacional está diante de sua constitucionalização ou diante de sua fragmentação -, ou se ambos não podem ser reais conjuta e paradoxalmente. Do efeito identificado por BROUDE, algumas possibilidades exsurgem: talvez tenha a discussão se tornado cansativa e sido levada a exaustão, o que é pouco provável; talvez o relatório tenha sido dotado de autoridade argumentativa de tal forma incisiva que o debate tenha esmorecido por reconhecimento dos acertados pontos de vistas do relatório; mas talvez, a discussão de um modo geral, incluindo o relatório, tenha sido conduzida à percepção de que há por trás de seus questionamentos básicos dúvidas ainda mais profundas, incluindo a possibilidade de realidades complexas contar com a convivência (pacífica?) de fenômenos antagônicos no mesmo espaço. Neste caso, a dificuldade aqui apontada se refere à reunião de bases 
epistemológicas apropriadas para percepção e discussão do que se tem chamado de pósmodernidade. Essas são algumas possibilidades sobre o possível esmorecimento do debate, embora se possa dizer que a observação de BROUDE, caso correta, seja uma verdade relativa: há ainda estudiosos, vide LEATHLEY, que retratam a fragmentação como ameaça à unidade do sistema jurídico internacional.

De um jeito ou de outro, as bases materiais sobre as quais o debate se põe continuam presentes, para serem debatidas. 


\section{REFERÊNCIAS BIBLIOGRÁFICAS}

ABI-SAAB, Georges; Fragmentation or unification: some concluding remark; in New York Journal of International Law and Politics (1999).

ACCIOLY, Hildebrando; NASCIMENTO, G.E; CASELLA, P.B.; Manual de Direito Internacional Público; Editora Saraiva; 19ª Edição; São Paulo/SP.

ANDENAS, Mads; Reassertion and Transformation: From Fragmentation to Convergence in International Law; Georgetown Journal of International Law; Volume 46; 2015.

AUST, August; Modern Treaty Law and Practice; Cambridge University Press; Second Edition; New York/2007.

BENVENISTI, Eyal; The Conception of International Law as a Legal System; German Yearbook of International Law; Volume 50; pp. 393 - 405; 2008.

BOWRING, Bill; Fragmentation, lex specialis and the tensions in the jurisprudence of the European Court of Human Rights; Journal of Conflict \& Security Law - Oxford University Press; 2010.

BROUDE, Tomer; Keep Calm and Carry On: Martti Koskenniemi and the Fragmentation of International Law; Temple International \& Comparative Law Journal; Volume 27; $\mathrm{n}^{\circ}$ 2; 1 de maio de 2013.

BUSCH, Marc L; Overlapping Institutions, Forum Shopping, and Dispute Settlement in International Trade; in International Organization, Volume 61; 2007.

CALTI, Melissa Zekiye; Methods of Norm Conflict Avoidance in International Law Applied to the Relationship Between Human Rights Law and Humanitarian Law: Fragmentation or Harmonisation? - The Applicability of Human Rights Treaties in The Context of Armed Conflicts; Master thesis, University of Oslo, 2014. 
CANÇADO TRINDADE, Antônio Augusto; The Merits of Coordination of International Courts on Human Rights; in Journal of International Criminal Justice; 2004.

CANNIZZARO, Enzo; Interconnecting International Jurisdictions: a Contribution from the Genocide Decision of the ICJ; European Journal of Legal Studies; Volume I; ${ }^{\circ}$ I; 2007; disponível em: http://www.ejls.eu/1/5UK.pdf (último acesso em 16.8.2016).

CASELLA, P. B; Fundamentos do Direito Internacional Pós-Moderno; Editora Quartier Latin do Brasil; São Paulo - 2008.

CASSESE, Antonio; International Law; Oxford University Press; 2a Edição; 2005.

CHARNEY, Jonathan I.; Is International Law threatened by Multiple International Tribunals?; in 271 Recueil des Cours de l'Academie de Droit International de la Haye; 1998.

Comissão de Direito Internacional das Nações Unidas; Fragmentation of International Law: Difficults Arising From the Diversification and Expansion of International Law: Report of the Study Group of the International Law Commission Finalized by Martti Koskenniemi (A/CN.4/L.682); abril de 2006. Disponível em:

http://legal.un.org/avl/ha/fil/fil.html (último acesso em: 12.11.2016).

; Report of the Study Group on

Fragmentation of International Law (A/CN.4/L.628); Agosto de 2002. Disponível em: http://legal.un.org/ilc/guide/1_9.shtml (último acesso: 12.11.2016).

; Report of the Study Group on Fragmentation of

International Law: Difficults Arising from the Diversification and Expansion of International Law (A/CN.4/L.644); 18 de julho de 2003. Disponível em: http://legal.un.org/ilc/guide/1_9.shtml (último acesso: 12.11.2016).

DALLARI, Pedro B. de Abreu; Atualidade dos Tribunais Administrativos de Organizações Internacionais; Tese apresentada na Faculdade de Direito da Universidade de São Paulo, para obtenção do título de Livre Docente; 2009. 
DEL MAR, Maksymilian; System Values and Understanding Legal Language; Leiden Journal of International Law; Volume 21; 2008.

DEL NEGRO, Guilherme; “The Weight of Obligations": Systemic Integration, Balancing and Conflicts Of Legitimacy; in Fragmentação do Direito Internacional - Pontos e Contrapontos; Arraes Editores; Belo Horizonte/MG - 2015.

DUPUY; Pierre-Marie; L'unité de l'ordre juridique international; in 297 Recueil des Cours de l'Academie de Droit International de la Haye; 2002.

FABRICOTTI, Alberta; The Paradox of Multilateralizing Regionalism Through Flexibility; in Multilateralizing Regionalism and The Future Arquitecture of International Trade Law As a System of Law; American Society of International Law (2009).

FASSBENDER, Bardo; The Meaning of International Constitutional Law; in Transnational Constitutionalism - International and European Perspectives; Cambridge University Press; 2007.

FISHER-LESCANO, Andreas e TEUBNER, Gunther; Regime Collisions: The Vain Search for Legal Unity in the Fragmentation of Global Law; in Michigan Journal of International Law; Volume 25; nº 4; 2004.

FRIEDMANN; Wolfgang; Mudança de Estrutura do Direito Internacional; Editora Freitas Bastos; Rio de Janeiro/RJ; 1971.

GALINDO, George Rodrigo Bandeira; Dialogando na Multiplicação: uma Aproximação; Revista de Direito Internacional; Brazilian Journal of International Law; Volume 9; jul/dez $-2012$.

(Org.); Introdução: Dialética Negativa?; in Fragmentação do Direito Internacional - Pontos e Contrapontos; Arraes Editores; Belo Horizonte/MG 2015.

GALINDO, George Rodrigo Bandeira; FELIX, Loussia Penha Musse; Pessoal Diplomático e Consular dos Estados Unidos em Teerã (Estados Unidos vs. Irã) (24 de Maio de 1980); in O Direito Internacional em Movimento: Jurisprudência Internacional Comentada - Corte Internacional de Justiça e Supremo Tribunal Federal; João Henrique 
Ribeiro Roriz e Alberto do Amaral Júnior (Orgs.); Instituto Brasiliense de Direito Civil; Grupo de Pesquisa Crítica e Direito Internacional; Brasília - DF/2016 (disponível em: https://www.academia.edu/28893710/O_Direito_Internacional_em_Movimento_Jurisprud \%C3\%AAncia_Internacional_Comentada_-

_Corte_Internacional_de_Justi\%C3\%A7a_e_Supremo_Tribunal_Federal). Último acesso: 2/1/2017.

GHOURI, Ahmad Ali; Is Characterization of Treaties a Solution to Treaty Conflicts?; Chinese Journal of International Law; Volume 11; pp. 247-280; 2012.

GOURGOURINIS, Anastasios; General/Particular International Law and Primary/Secondary Rules: Unitary Terminology of a Fragmented System; The European Journal of International Law; Volume 22; n 4; 2011.

GUILLAUME, Gilbert; The Proliferation of International Judicial Bodies: the Outlook for the International Legal Order - Speech by His Excellency Judge Gilbert Guillaume, President of the International Court of Justice, to the Sixth Committee of the General Assembly of the United Nations; 2000. Disponível em: http://www.icj-

cij.org/court/index.php?pr=85\&pt=3\&p1=1\&p2=3\&p3=1 (Último acesso em: 29.9.2015).

HAFNER, Gerhard; Pros and Cons Ensuing from Fragmentation of International Law; in (849) Michigan Journal of International Law; Volume 25; 2003 - 2004.

; Risks Ensuing From Fragmentation of International Law; Syllabuses on Topics Recommended for Inclusion in the Long-Term Programme of Work of the Comission (A/55/10) -2000. Disponível em: http://legal.un.org/ilc/guide/1_9.shtml (último acesso: 12.11.2016).

JENKS, Wilfred; El Derecho comum de la humanidade; Editorial Tecnos; Madrí - 1968.

; The Conflicts of Law-Making Treats Treaties; in The British Year Book of International Law; 1953.

JOYNER, Daniel H.; ROSCINI, Marco (Ed.); Non-Proliferation Law As a Special Regime: a Contribution to Fragmentation Theory in International Law; Cambrigde University Press; 2012. 
JUENGER, Friedrich K.; Forum Shopping, Domestic and International; in Law Journal Library; Tulane Law Review; 63 Volume; 1988 - 1999.

KINGSBURY, Benedict; Foreword: Is the Proliferation of International Courts and Tribunals a Systematic Problem?; New York University Journal of International Law and Politics; Volume 30; 1999.

KOSKENNIEMI, Martti; The Fate of Public International Law: Between Technique and Politics; Modern Law Review - Volume 70; 2007.

International Law: Between Fragmentation and

Constitucionalism; Canberra - 2006. Disponível em:

http://www.helsinki.fi/eci/Publications/talks_papers_MK.html. (Último acesso em: 4.11.2016).

KOSKENNIEMI, Martti; LEINO, Päivi; Fragmentation of International Law? Postmodern Anxieties; Leiden Journal of International Law; 2002.

LAVRANOS, Nikolaos; The Solange-Method as a Tool for Regulating Competing Jurisditions Among International Courts and Tribunals; Law Journal Library Loyola of Los Angeles International and Comparative Law Revi; 2008.

LEATHLEY, Christian; An Institutional Herarchy to Combat the Fragmentation of International Law: Has the ILC Missed an Opportunity?; New York University Journal of International Law and Politics; Volume 40:259; 2007.

MATZ-LÜCK, Nele; Structural Question of Fragmentation; in Fragmentation of International Legal Orders and International Law: Ways Forward?; American Society of International Law; 2011.

MARCEAU, Gabrielle; Conflicts of Norms and Conflicts of Jurisdiction - The Relationship between the WTO Agreement and MEAs and other Treaties; in Journal of World Trade; Volume 30; 2001. 
International Trade Law As a Sustem of Law; American Society of International Law; 2009.

MICHAELS, Ralf; PAUWELYN, Joost; Conflict of Norms or Conflict of Laws? Different Techiniques in the Fragmentation of Public International Law; Duke Journal of Comparative \& International Law; Volume 22; Iss. 3; 349 - 376.

MIKO, Samantha A.; Norm Conflict, Fragmentation, and the European Court of Human Rights; Boston College Law School Review (1351); 2013.

MILANOVIC, Marko; Norm Conflict in International Law: Whither Human Rights?; Duke Journal of Comparative \& International Law; Volume 20; $n^{\circ}$ 1; 2009.

MURPHY, Sean D.; Deconstructing Fragmentation: Koskenniemi's 2006 ILC Project; Temple International \& Comparative Law Journal; Forthcoming; GWU Law School Public Law Research Paper nº 2013-109; 14 de Junho de 2013.

PAUWELYN, Joost; SALLES, Luiz Eduardo; Tribunals: (Real) Concerns and (Im) Possible Solutions; Cornell International Law Journal; Volume 42; 2009.

PAUWELYN, Joost; Multilateralizing Regionalism: What About na MFN Clause In Preferential Trade Agreements?; in Multilateralizing Regionalism and The Future Architecture Of International Trade Law As a Systema Of Law; American Society of International Law; 2009.

; Conflitc of Norms in Public International Law - How WTO Law Relates to Other Rules of International Law; Cambridge Studies in International and Comparative Law; 2003.

PAVEL, Carmen; Normative Conflict in International Law; San Diego Law Review; Volume 46; 2009.

PROST, Mario; CLARK, Paul Kingsley; Unity, Diversity and the Fragmentation of International Law: How Much Does the Multiplication of International Organizations Really Matter?; Chinese Journal of International Law; Volume 5, nº 2, 341 - 370; 2006. 
PUDER, Markus G.; The Rise of Regional Integration Law (RIL): Good News For International Environment Law (IEL)?; Georgetown International Environmental Law Review; Volume 23; 2011.

RACHOVITSA, Adamantia; Treaty Clause and Fragmentation of International Law: Appliying the More Favorable Protection Clause in Human Rights; Human Rights Law Review; Volume 16; pp. 77 - 101; 2016.

RAMANUJAN, Adarsh; Conflicts over "Conflict": Preventing Fragmentation of International Law; Trade, Law and Development; Volume 1; ${ }^{\circ}$ 1; 2009.

RAMOS, André de Carvalho; Direitos Humanos na Integração Econômica - Análise Comparativa da Proteção de Direitos Humanos e Conflitos Jurisdicionais na União Europeia e Mercosul; Editora Renovar; Rio de Janeiro - 2008.

Edição; São Paulo/SP - 2012 ; Processo Internacional de Direitos Humanos; Editora Saraiva; $2^{\mathrm{a}}$

RESEK, Francisco; Direito Internacional Público - Curso Elementar; Editora Saraiva; $14^{\mathrm{a}}$ Edição, 2013.

ROMANO, Cesare; The Proliferation of International Judicial Bodies: the Pieces of the Puzzle; New York University Journal of International Law and Politics; Volume 31; 1999.

SALIBA, Aziz Tuffi (org.); Direito dos Tratados - Comentários à Convenção de Viena sobre o Direito dos Tratados (1969); Editora Arraes; Belo Horizonte -MG (2011).

SCHWEBEL, Stephen; Adress to the Plenary Session of the General Assembly of the United Nations; 1999. Disponível em: http://www.icjcij.org/court/index.php?pr=87\&pt=3\&p1=1\&p2=3\&p3=1 (Último acesso em: 29.9.2015).

SHAW, Malcolm N.; Direito Internacional; Martins Fontes - 2010.

SHEFFER, Megan Wells; Bilateral Investment Treaties: A Friend or Foe to Human Rights?; Denver Journal of International Law and Policy (483); 22 de junho de 2011. 
SIMMA, Bruno; Fragmentation in a Positive Light; Michigan Journal of International Law; Volume 25 (845); 2003 - 2004.

SIMMA, Bruno; PULKOWSKI; Of Planets and The Universe: Self-contained Regimes in International Law; The European Journal of International Law; Volume 17; nº 3; 2006.

SIMO, Regis Yann; The Law of International Responsability: the Case of WTO As a "Lex Specialis" Or the Fallacy Of a 'Self-Contained' Regime; African Journal of International and Comparative Law; Volume 22; $n^{\circ} 2 ; 2014$.

SINGH, Sahib; Two Potential Paths Forward from Fragmentation Discourse: Sociology and Ethics; in Fragmentation of International Legal Orders and International Law: Ways Forward?; American Society of International Law; ASIL Proceedings; 2011.

TZEVELEKOS, Vassilis P.; The Use of Article 31 (3) (c) Of the VCLT In the Case Law Of the ECtHR: An Effective Anti-Fragmentation Tool Or A Selective Loophole For The Reinforcement Of Human Rights Teleology?; Michigan Journal Of International Law; Volume 31; 2010.

VAN MULLIGEN, Johannes Gerald; Global Constitucionalism and the Objective Purport of the International Legal Order; Leiden Journal of International Law - Universidade de Cambridge; Volume 24; 2011.

VARELLA, Marcelo Dias; A Crescente Complexidade do Sistema Jurídico Internacional - Alguns Problemas de Coerência Sistêmica; in Revista de Informação Legislativa; n. 167; Brasília/ 2005.

YOUNG, Margaret A.; Introduction: The Productive Friction between Regimes; in Regime Interaction in International Law: Facing Fragmentation; Editado por Margaret A. Young; Cambridge University Press - 2012. 


\section{JURISPRUDÊNCIA INTERNACIONAL CONSULTADA}

Corte Europeia de Direitos Humanos; Al-Adsani v. United Kingdom (application $\mathrm{n}^{\circ}$ 35763/97); julgado em 21 de novembro de 2001.

Corte Europeia de Direitos Humanos; Bankovic and others v. Belgium and others (application $\mathrm{n}^{\circ}$ 55207/99); apreciado em 12 de dezembro de 2001.

Corte Europeia de Direitos Humanos; Golder v. United Kingdom (application n ${ }^{\circ} 4451 / 70$ ); julgado em 21 de fevereiro de 1975.

Corte Europeia de Direitos Humanos; Marlène Belilos v. Switzerland (application $\mathrm{n}^{\circ}$ 10328/83); julgado em 29 de abril de 1988.

Corte Europeia de Direitos Humanos; Loizidou v. Turkey (application n ${ }^{\circ}$ 15318/1989); julgado em 18 de dezembro de 1996.

Corte Europeia de Direitos Humanos; Tatjana Slivenko and Others

v. Latvia (application $\mathrm{n}^{\circ}$ 48321/99); julgado em 9 de outubro de 2003.

Corte Interamericana de Direitos Humanos; Parecer Consultivo Sobre Outros Tratados Sujeitos à Jurisdição Consultiva da Corte (Parecer Consultivo n ${ }^{\circ}$ OC-1/82); 24 de setembro de 1982.

Corte Interamericana de Direitos Humanos; Caso "Velázquez Rodríguez v. Honduras"; julgamento em 29 de julho de 1988; série $\mathrm{C}$ n 4 .

Corte Internacional de Justiça; Caso Barcelona Traction, Light and Power Company, Limited (Bélgica v. Espanha); julgado em 5 de fevereiro de 1970..

Corte Internacional de Justiça; Caso das Atividades Militares e Paramilitares Na e Contra a Nicarágua (Niicarágua v. Estados Unidos da América); julgado em 27 de junho de 1986. 
Corte Internacional de Justiça; Caso do Estreito Corfu (Reino Unido da Grâ-Bretanha e Irlanda do Norte v. Albânia); julgado em 9 de abril de 1949.

Corte Internacional de Justiça; Caso Relativo à Aplicação da Convenção de Prevenção e Repressão aos Crimes de Genocídio (Bósnia-Hezergovina v. Iugoslávia - Sérvia e Montenegro); julgado em 26 de fevereiro de 2007.

Corte Internacional de Justiça; Caso Relativo ao Corpo Diplomático e Consular em Teerã (Estados Unidos da América v. Irã); julgado em 24 de maio de 1980.

Corte Internacional de Justiça; Caso Sobre Questões de Aplicação e Interpretação da Convenção de Montreal de 1971 Resultantes do Incidente Aéreo em Lockerbie (Líbia v. Estados Unidos da América); encerrado em 10 de setembro de 2003.

Corte Internacional de Justiça; Parecer Consultivo a Respeito de reservas à Convenção sobre Prevenção e Repressão ao Crime de Genocídio; 1951.

Corte Internacional de Justiça; Parecer Consultivo Sobre a Licitude da Ameaça ou Uso de Armas Nucleares; 1996.

Corte Internacional de Justiça; Parecer Consultivo Sobre as Consequências Jurídicas da Construção de um Muro no Território Palestino Ocupado; 2004.

Corte Permanente de Arbitragem; Caso Irlanda vs Reino Unido (Arbitragem OSPAR). Disponível em: http://www.pca-cpa.org/showpage.asp?pag_id=1158 (Último acesso em: 6.7.2015).

Corte Permanente de Arbitragem; Caso da Usina de MOX - Irlanda vs Reino Unido; Disponível em: http://www.pca-cpa.org/showpage.asp?pag_id=1148 (Último acesso em: 6.7.2015).

Corte Permanente de Justiça Internacional; Caso do "S.S. Winbledon"; julgado em 17 de agosto de 1923.

Corte Permanente de Justiça Internacional; Caso "Mavrommatis Palestine Concessions"; julgado em 30 de agosto de 1924. 
Corte Permanente de Justiça Internacional; Parecer Consultivo sobre "Customs Regime between Germany and Austria”; prolatado em 5 de setempro de 1931.

Corte Permanente de Justiça Internacional; Caso Oscar Chinn; julgado em 12 de dezembro de 1934.

Organização das Nações Unidas; Affaire concernant l'apurement des comptes entre le Royaume des Pays-Bas et la République Française en application du Protocole du 25 septembre 1991 additionnel à la Convention relative à la protection du Rhin contre la pollution par les chlorures du 3 décembre 1976; Reports of International Arbitral Awards; 12 de maio de 2004.

Organização das Nações Unidas; Southern Bluefin Tuna Case Between Australia and Japan and Between New Zealand and Japan, Award on Jurisdiction and Admissibility; Reports of International Arbitral Awards; 4 de agosto de 2000.

Organização Mundial do Comércio; "European Communities - Measures Concerning Meat and Meat Products (Hormones)"; 13 de fevereiro de 1998 (WT/DS26/AB/R, WT/DS48/AB/R).

Organização Mundial do Comércio; European Communities - Measures Affecting the Approval and Marketing of Biotech Products (WT/DS291/R).

Organização Mundial do Comércio; "Chile - Measures affecting the transit and importation of swordfish" (WT/193/1).

Organização Mundial do Comércio; "Korea - Measures Affecting Government Procurement" (WT/DS163/R).

Organização Mundial do Comércio; "Turkey - Restrictions on Imports of Textile and Clothing Products" (WT/DS34/R).

Organização Mundial do Comércio; "United States - Import Prohibition of Certain Shrimp and Shrimp Products” (WT/DS58/AB/R). 
Organização Mundial do Comércio; "United States - Standards for Reformulated and Conventional Gasoline" (WT/DS2/AB/R).

Tribunal Internacional Para o Direito do Mar; Pedido de Medidas Provisórias da Irlanda Disponível em: https://www.itlos.org/cases/list-of-cases/case-no-10/ (Último acesso em: 6.7.2015).

Tribunal Internacional Para o Direito do Mar; Chile vs. European Union, Case on conversation of swordfish stocks between Chile and the European Community in the southeastern pacific ocean. Disponível em: https://www.itlos.org/cases/list-of-cases/case-no-7/. (Último acesso em: 5.10.2015).

Tribunal Internacional Para o Direito do Mar; Southern Bluefin Tuna Cases (New Zealand v. Japan; Australia v. Japan) - Provisional Measures; decidido em 27 de agosto de 1999. 